San Jose State University

SJSU ScholarWorks

Master's Theses

Master's Theses and Graduate Research

Spring 2015

\title{
Synthesis of a Ditopic Verdazyl Ligand and Investigation of its Coordination to Transition Metals
}

Erik Charles Johnson

San Jose State University

Follow this and additional works at: https://scholarworks.sjsu.edu/etd_theses

\section{Recommended Citation}

Johnson, Erik Charles, "Synthesis of a Ditopic Verdazyl Ligand and Investigation of its Coordination to Transition Metals" (2015). Master's Theses. 4545.

DOI: https://doi.org/10.31979/etd.qbvm-6rn9

https://scholarworks.sjsu.edu/etd_theses/4545

This Thesis is brought to you for free and open access by the Master's Theses and Graduate Research at SJSU ScholarWorks. It has been accepted for inclusion in Master's Theses by an authorized administrator of SJSU ScholarWorks. For more information, please contact scholarworks@sjsu.edu. 


\title{
SYNTHESIS OF A DITOPIC VERDAZYL LIGAND AND INVESTIGATION OF ITS COORDINATION TO TRANSITION METALS
}

\author{
A Thesis \\ Presented to \\ The Faculty of the Department of Chemistry \\ San José State University
}

\author{
In Partial Fulfillment \\ of the Requirements for the Degree \\ Master of Science
}

by

Erik C. Johnson

May 2015 
(C) 2015

Erik C. Johnson

ALL RIGHTS RESERVED 
The Thesis Committee Approves the Thesis Titled Synthesis of a Ditopic Verdazyl Ligand and Investigation of its Coordination to Transition Metals

by

Erik C. Johnson

APPROVED FOR THE DEPARTMENT OF CHEMISTRY SAN JOSÉ STATE UNIVERSITY

May 2015

Dr. David Brook

Department of Chemistry

Dr. Daniel Straus

Department of Chemistry

Dr. Roger Terrill

Department of Chemistry 


\begin{abstract}
SYNTHESIS OF A DITOPIC VERDAZYL LIGAND AND INVESTIGATION OF ITS COORDINATION TO TRANSITION METALS
\end{abstract}

by Erik C. Johnson

The goal of this research project was to prepare a self-assembled grid complex with a ditopic bis-verdazyl ligand and nickel(II) ions. A verdazyl is a relatively stable type of organic free radical in which the unpaired electron is delocalized over four nitrogen atoms. The ditopic verdazyl ligand was synthesized in six steps, and its coordination to metal ions, in particular $\mathrm{Ni}^{2+}$, was investigated. The hypothesized complex of the ligand with $\mathrm{Ni}^{2+}$ is potentially functional as a molecular magnet due to the free radical nature of the ligand; hence, the complex could be useful for information storage. The ligand was definitively characterized by mass spectrometry and ESR. The results of variable temperature ESR performed on the ligand dissolved in toluene at low temperatures indicate that the ground state of the diradical ligand is a singlet state rather than a triplet state. Infrared spectroscopy was also performed on the ligand and the resulting spectra indicated the presence of the correct functional groups of the ligand that was planned in the original design of the project. The characterization of the ligand was followed up with a number of semi-empirical A1 calculations on simpler systems to determine why the ground state of the ligand was a singlet state rather than a triplet state. The coordination compound of the ligand and $\mathrm{Ni}(\mathrm{II})$ was characterized by UV-visible spectrometry. In addition, ESI-MS was performed on the coordination compound, and the mass-to-charge ratio of the anticipated grid complex in a +1 oxidation state was observed. This ESI result was convincing evidence that self-assembly occurred. The coordination compound of the ligand with nickel will be further characterized by techniques for measuring magnetic 
susceptibility and electrochemistry. If possible, X-ray crystallography will be performed on crystals of the compound. 


\section{TABLE OF CONTENTS}

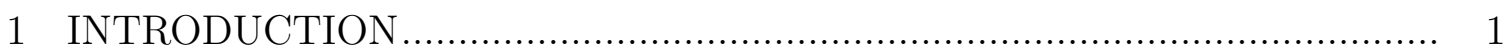

2 EXPERIMENTAL PROCEDURES ...................................................... 41

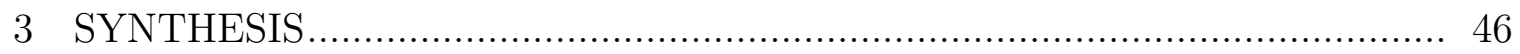

4 CHARACTERIZATION AND PROPERTIES ...................................... 48

5 CONCLUSION .......................................................................... 60

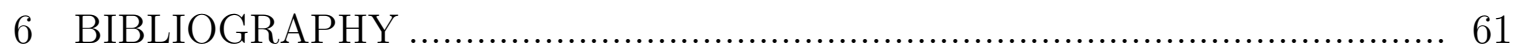




\section{List of Figures}

2 Porphyrin ring and $\mathrm{R}$ groups for porphyrin triangle complex. $\mathrm{R}$ can be either R1 or R2 depending on the complex. The two $\mathrm{R}$ groups are for increased solubility. . . . . . . . . . . . . . . . . 1

1 Porphyrin triangle complex. The porphyrin rings have been simplified to make the structure more easily understood. . . . . . . . . . . . . 2

3 Square complex. . . . . . . . . . . . . . . . . 3

4 Ligand for circular helicate with iron (II). . . . . . . . . . . . . . 4

5 Circular helicate with iron (II), 5-pointed star shaped version. . . . . 4

$6 \quad$ (a) - (c): Self-assembly of a rotaxane: (a) First step; (b) second step; (c) third step. . . . . . . . . . . . . . . . . . . . 7

7 Ligand that switches shape from "W" to "U" when complexed with $\mathrm{Pb}(\mathrm{II}) \ldots \ldots \ldots \ldots$. . . . . . . . . . . . . . . 8

8 Ligand termed "molecular tweezers." R1 is n-butyl. R2 is either n-hexyl or 2-ethylhexyl. . . . . . . . . . . . . . . . . . . . 9

9 Ligand coordinated to a metal ion; the shape has changed from "W"

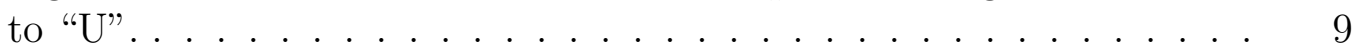

10 Grid complex. $R=$ phenyl or $p-\mathrm{C}_{6} \mathrm{H}_{4}-\mathrm{N}\left(\mathrm{CH}_{3}\right)_{2}$. . . . . . . . . . . 10

11 Self-assembly of copper(I) grid. . . . . . . . . . . . . . . . . . . 11

12 Macrocyclic ligand. . . . . . . . . . . . . . . . . . . . 11

13 Grid complex formed from the macrocyclic ligand and copper(I), crystal structure. . . . . . . . . . . . . . . . . . . 12

$14 \quad 6,6^{\prime}$-bis $[2$-(6-methylpyridyl)]-3,3'-bipyridazine. . . . . . . . . . 13

15 Crystal structure of $[3 \times 3]$ grid complex made with silver(I) and the ligand 6,6'-bis[2-(6-methylpyridyl)]-3,3'-bipyridazine. . . . . . . . . . . 13

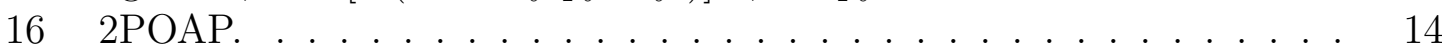

17 Crystal structure of $[3 \times 3]$ grid made from manganese(II) and 2 POAP. 14

18 Grid complex with pyrazine rings filling the pores. . . . . . . . . . 15

19 2-tiered ruthenium rack self-assembled structure. . . . . . . . . . . 17

20 3-tiered ruthenium rack self-assembled structure. . . . . . . . . . . . . 17

$21 \quad$ o-iminobenzosemiquinonate radical, $\left[\mathrm{L}^{\mathrm{ISQ}}\right]^{1-} \ldots \ldots \ldots \ldots$

$22 \quad\left[\mathrm{Co}^{\mathrm{III}}\left(\mathrm{L}^{\mathrm{ISQ}}\right)_{3}\right], \mathrm{X}$-ray crystal structure. . . . . . . . . . . . . . 20

$23\left[\mathrm{Cu}^{\mathrm{II}}(\right.$ dmtacn $\left.)\left(\mathrm{L}^{\mathrm{ISQ}}\right)^{1-}\right]$; dmtacn = 1,4-dimethyl-1,4,7-triazacyclononane. 21

24 Reduced form of the 2,2'-bipyridineCp* $\mathrm{Rh}$ Complex; $\mathrm{Cp}^{*}=\eta^{5}$ -

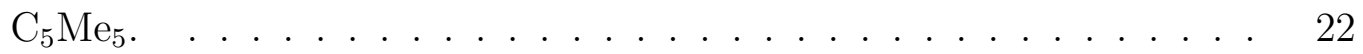

25 General structure of complexes of iron(II) with organic free radical ligands. . . . . . . . . . . . . . . . . . . . 23

26 Ligands for iron (II) complexes. . . . . . . . . . . . . . . . . . 23

27 Ligands for molybdenum and tungsten complexes. . . . . . . . . . . . 24 
28 Ligands that can adopt a radical form, along with a nickel complex of one of them. . . . . . . . . . . . . . . . . . 25

29 Ligands for $\mathrm{Ni}, \mathrm{Pd}$, Pt complexes. . . . . . . . . . . . . 26

30 Complex of a metal with $\mathrm{L}^{I S Q}$ ligand. $M$ is either $\mathrm{Ni}, \mathrm{Pd}$, or Pt. . . 26

31 Nitronyl nitroxide ligand for $\mathrm{Mn}(\mathrm{II})$ complex. . . . . . . . . . . . . 27

32 2-2-pyridyl nitronyl nitroxide ligand for $\mathrm{Mn}(\mathrm{II})$ and $\mathrm{Ni}(\mathrm{II})$ complexes. 28

33 Nickel nitronyl nitroxide complex, X-ray crystal structure. $\quad \ldots \ldots . \quad 29$

34 4-QNNN Mn(II) complex, X-ray crystal structure. . . . . . . . 30

35 HLnit, the nitronyl nitroxide ligand used for the $[2 \times 2]$ grid complex

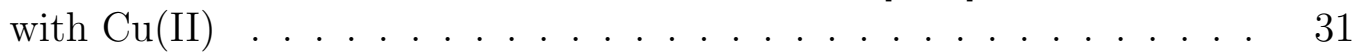

36 Copper(II) grid complex of the HLnit ligand, X-ray crystal structure. 32

37 First reported synthesis of a verdazyl . . . . . . . . . . . . . . 33

38 First reported synthesis of a 6 -oxoverdazyl. . . . . . . . . . . 33

39 Terpyridine analog verdazyl, bipyvd. . . . . . . . . . . . . . 34

40 Benzene-bridged verdazyls. . . . . . . . . . . . . . . . . 35

41 Bisverdazyl copper(I) complex with iodide as a bridging ligand. . . . 36

42 Verdazyl copper(I) complex with bromides as bridging ligands, X-ray crystal structure. . . . . . . . . . . . . . . . . . 36

43 Verdazyl copper(I) complex, X-ray crystal structure. . . . . . . . . 37

44 X-ray crystal structure of verdazyl copper(I) complex, in which isopropyl groups are attached to the verdazyl. . . . . . . . . . . . . . . 38

$45 \quad 1,5$-dipyridylverdazyl. . . . . . . . . . . . . . . . . . . . 39

46 Nickel(II) complex of 1,5-dipyridylverdazyl, X-ray crystal structure. . 40

47 Ditopic bis-verdazyl ligand. . . . . . . . . . . . . . . . . . . . 41

48 Synthesis, including triphosgene reaction, deprotection, and oxidation. 46

49 Energy diagram for a monoradical. . . . . . . . . . . . . . . 50

50 Energy diagram for a diradical. . . . . . . . . . . . . . . . . . 51

51 Energy diagram for a diradical, showing zero-field splitting. . . . . . . 51

52 First derivative of ESR absorption spectrum of ditopic verdazyl ligand in frozen toluene, main part of the spectrum. . . . . . . . . . . 52

53 Illustration of how to calculate the $D^{\prime}$ parameter from the ESR spectrum in frozen toluene. . . . . . . . . . . . . . . . . . 52

54 First derivative of ESR absorption spectrum of ditopic verdazyl ligand in frozen toluene, half-field spectrum. . . . . . . . . . . . . . 53

55 Variable-temperature ESR results and curve-fitting. . . . . . . . . 53

56 MO diagrams representing 10-atom molecules and pictures of HOMOs based on semi-empirical AM1 calculations. Pictures of HOMOs on the left, as well as the MO diagram on the left, are for 1,3-dimethylene benzene diradical, and pictures of HOMOs on the right, as well as the $\mathrm{MO}$ diagram on the right, are for 4,6 dimethylene pyrimidine diradical. . . . . . . . . . . . . . . . . . . 56 56

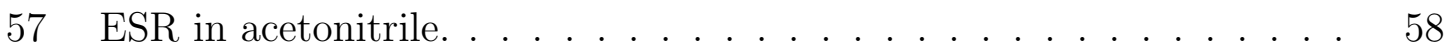


58 Titration data. . . . . . . . . . . . . . . . . . . . 59 


\section{List of Tables}

1 Reduction potentials of the cobalt grid complex shown in Figure 10. The potentials are measured in reference to ferrocene. . . . . . . . . 16 


\section{INTRODUCTION}

Self-assembly is, according to Lehn et al.: "the spontaneous but directed formation of a closed superstructure or polymer from a mixture of components (organic ligands, salt crystals, and sometimes molecules of solvents). The product exhibits a notable thermodynamic and kinetic stability and its components should contain all the information necessary for a correct assembly to occur." 1

Metal coordination and hydrogen bonding are two possible ways of directing a self-assembly process. There are thousands of different configurations that the molecule could potentially adopt, but only one is formed in the self-assembly process.

Zinc and porphyrin and pyridine ligands self-assembled to form triangle shaped complexes in research done by Chi, Guerin et al. ${ }^{2}$ (Figures 1, 2).
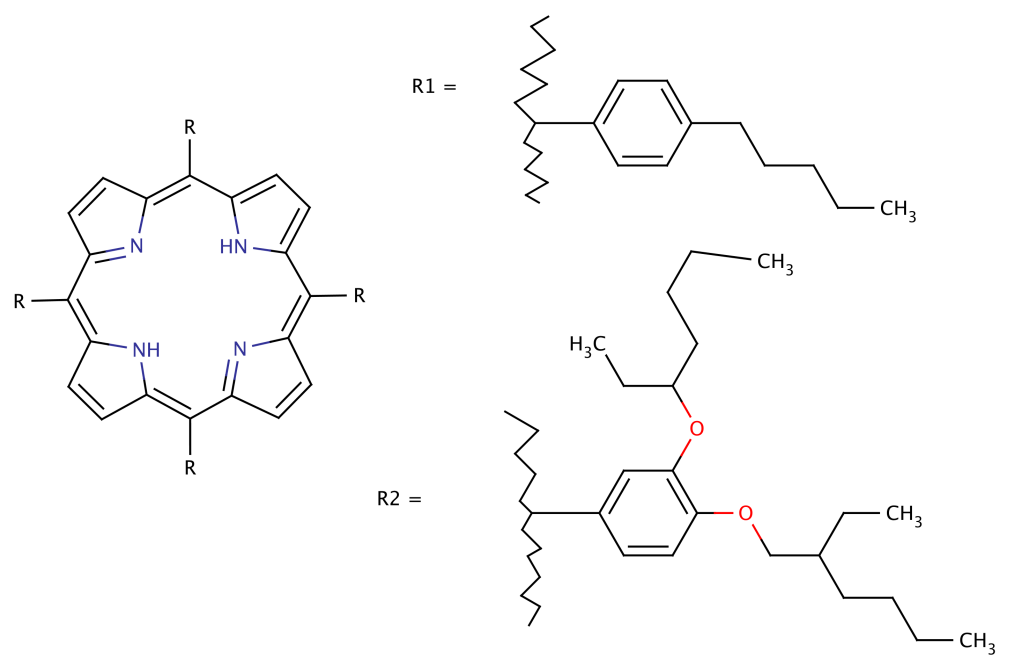

Figure 2. Porphyrin ring and $\mathrm{R}$ groups for porphyrin triangle complex. $\mathrm{R}$ can be either $\mathrm{R} 1$ or $\mathrm{R} 2$ depending on the complex. The two $\mathrm{R}$ groups are for increased solubility. 


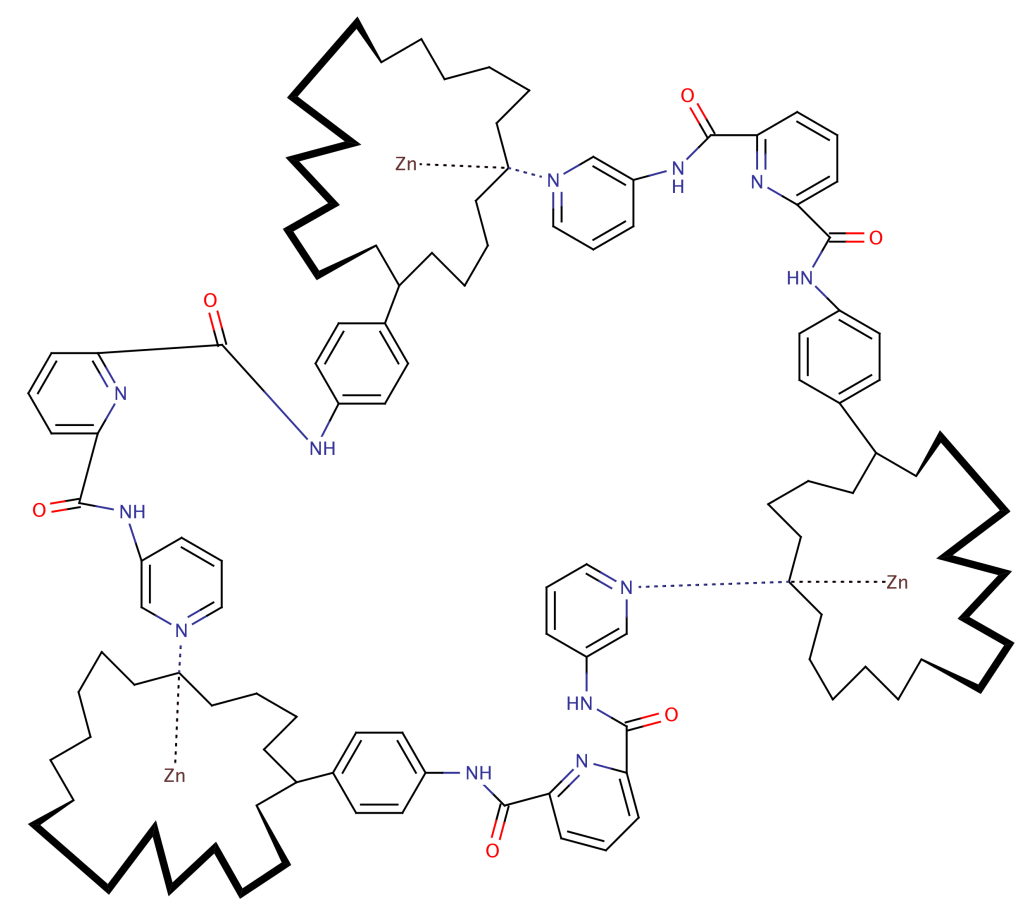

Figure 1. Porphyrin triangle complex. The porphyrin rings have been simplified to make the structure more easily understood.

Triangles are not the only polygonal shape assumed by a self-assembled complex; square complexes have been formed by self-assembly too. A square complex was formed by AlQaisi et al. ${ }^{3}$ from platinum and alkynes and bidentate phosphorus ligands containing four cyclohexane groups each (Figure 3). 


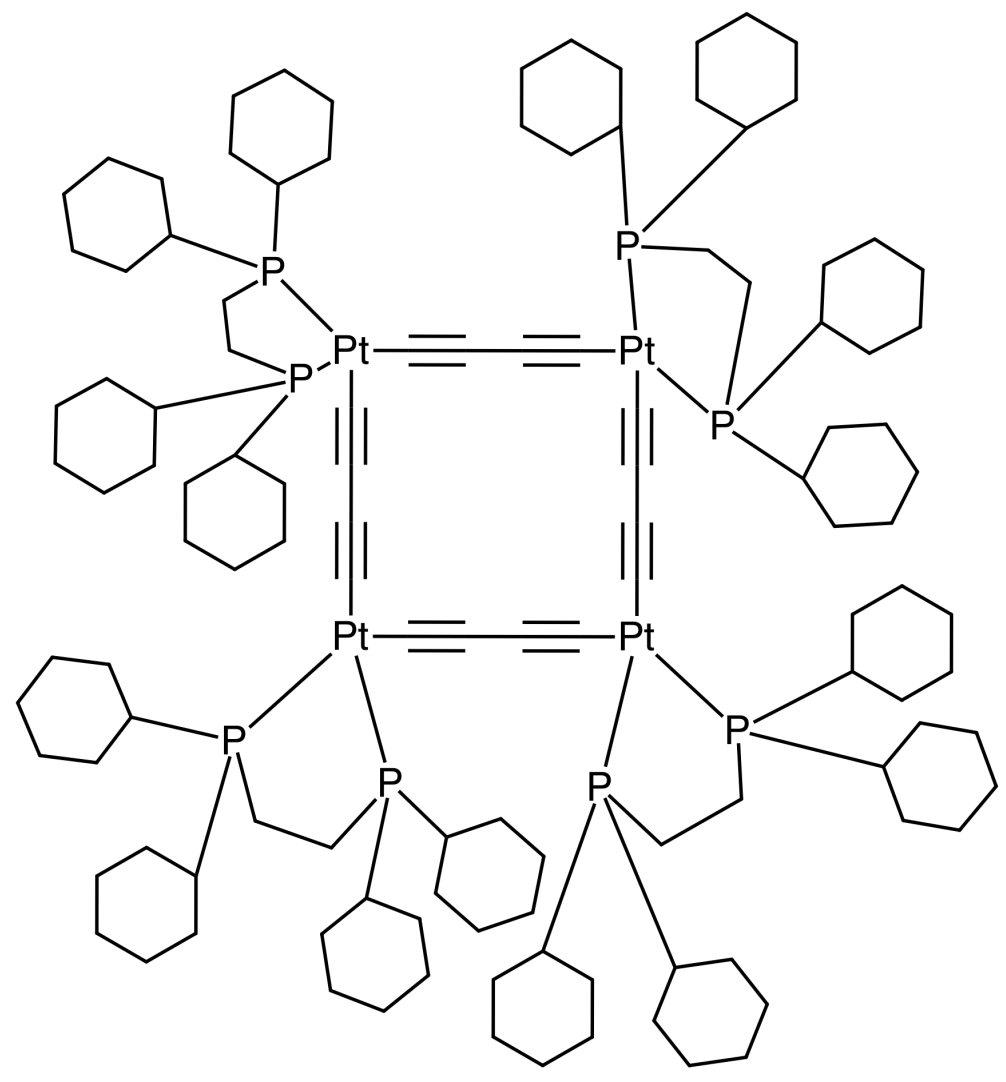

Figure 3. Square complex.

Another form of a self-assembled complex is a circular helicate. Jean-Marie Lehn and his colleagues ${ }^{4}$ formed circular helicates with iron (II) and a ligand containing six pyridines. Depending on the ion present in solution, four-, five-, or six-pointed circular helicates can result. A chloride anion in solution resulted in a five-pointed star-shaped circular helicate forming around the anion. The ligand is shown in Figure 4, while the circular helicate complex is shown in Figure 5. 


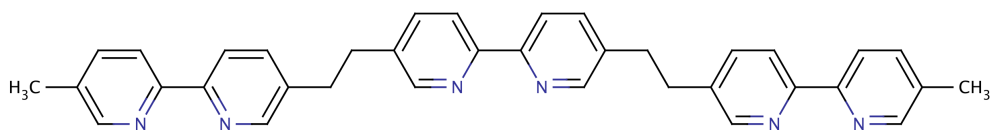

Figure 4. Ligand for circular helicate with iron (II).

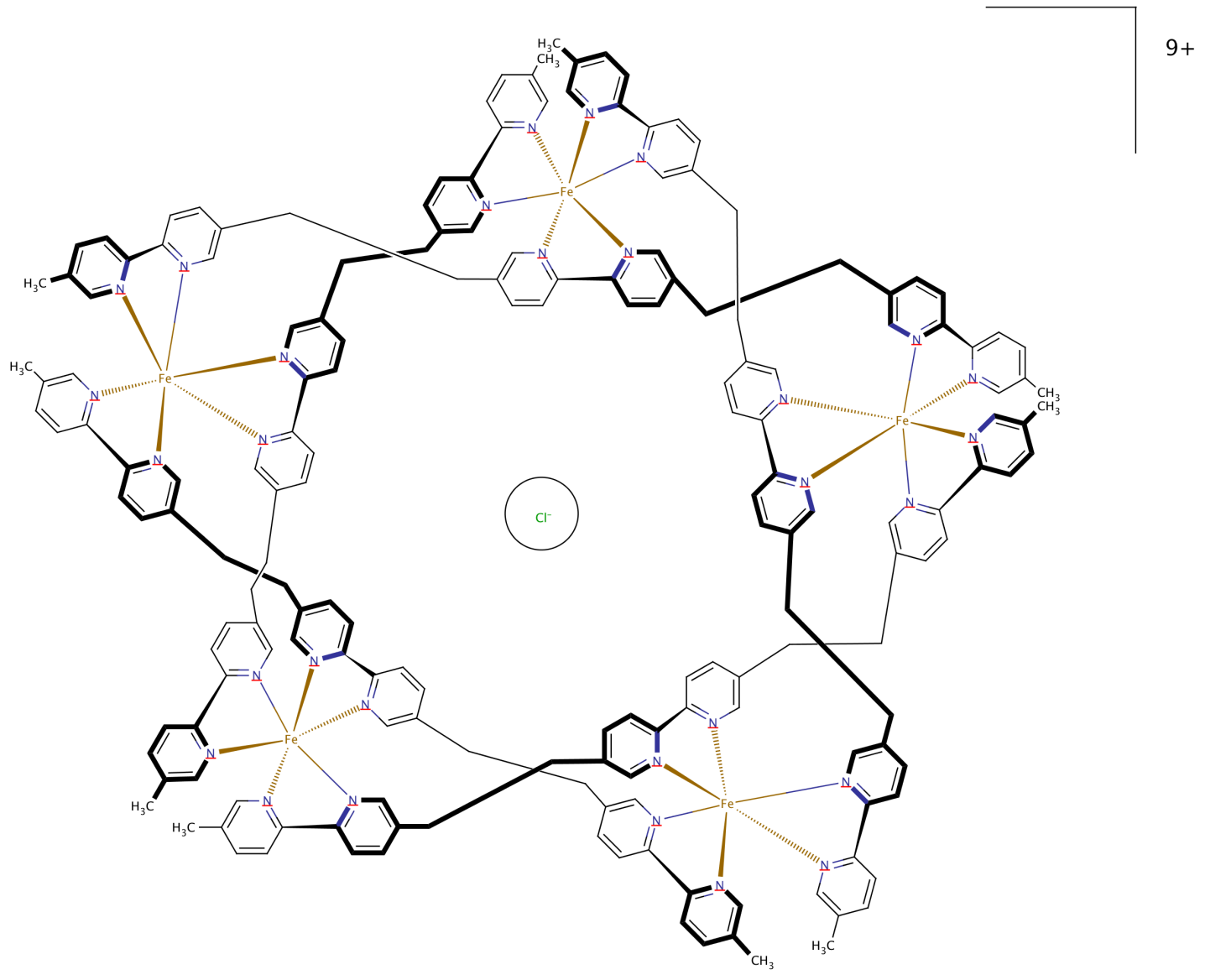

Figure 5. Circular helicate with iron (II), 5-pointed star shaped version.

Lehn ${ }^{5}$ also formed cylinders through self-assembly using either silver(I) or copper(I) ions to drive the assembly. 
Rotaxanes are defined as: "molecular systems consisting of a string threaded through one or more rings, the two ends of the string bearing bulky groups acting as stoppers and preventing the molecular string from dethreading." ${ }^{6}$ An example of a rotaxane comes from the work of Cárdenas et al. ${ }^{6}$, and the self-assembly of the rotaxane involves coordination of both the string and the ring to a copper(I) ion. Figure 6 depicts the reaction to form this rotaxane through self-assembly.

(a)

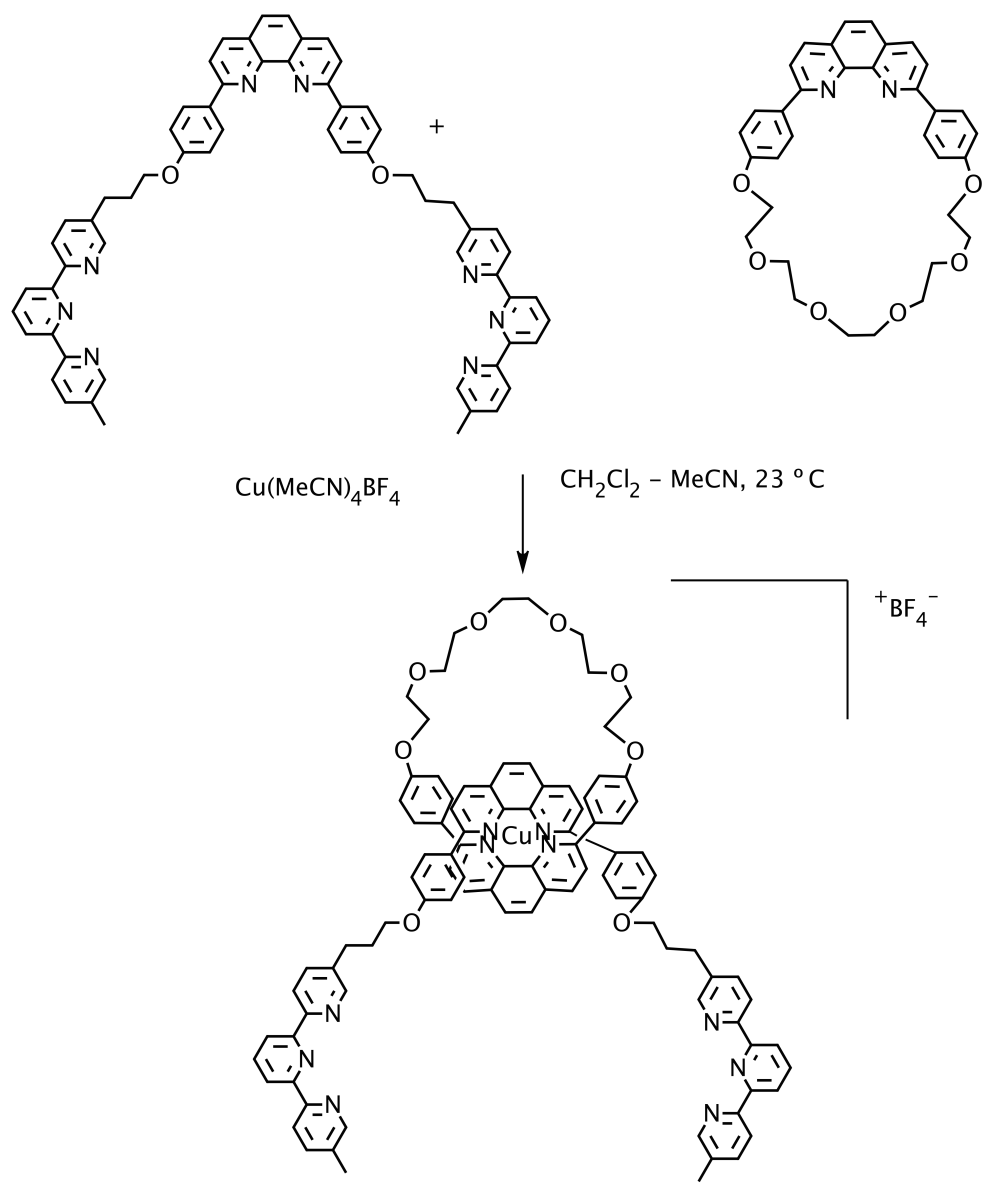


(b)

1.

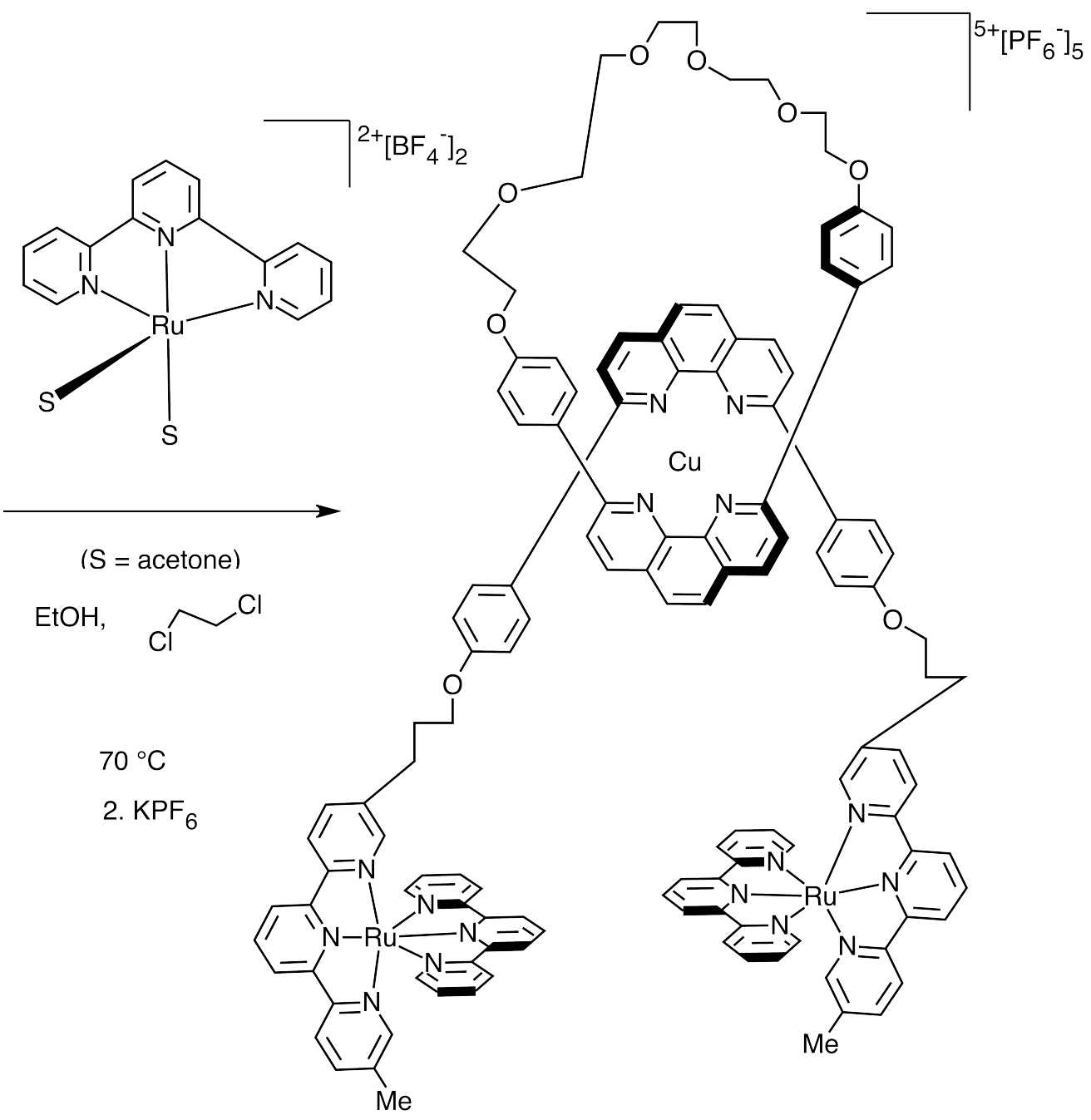


(c)

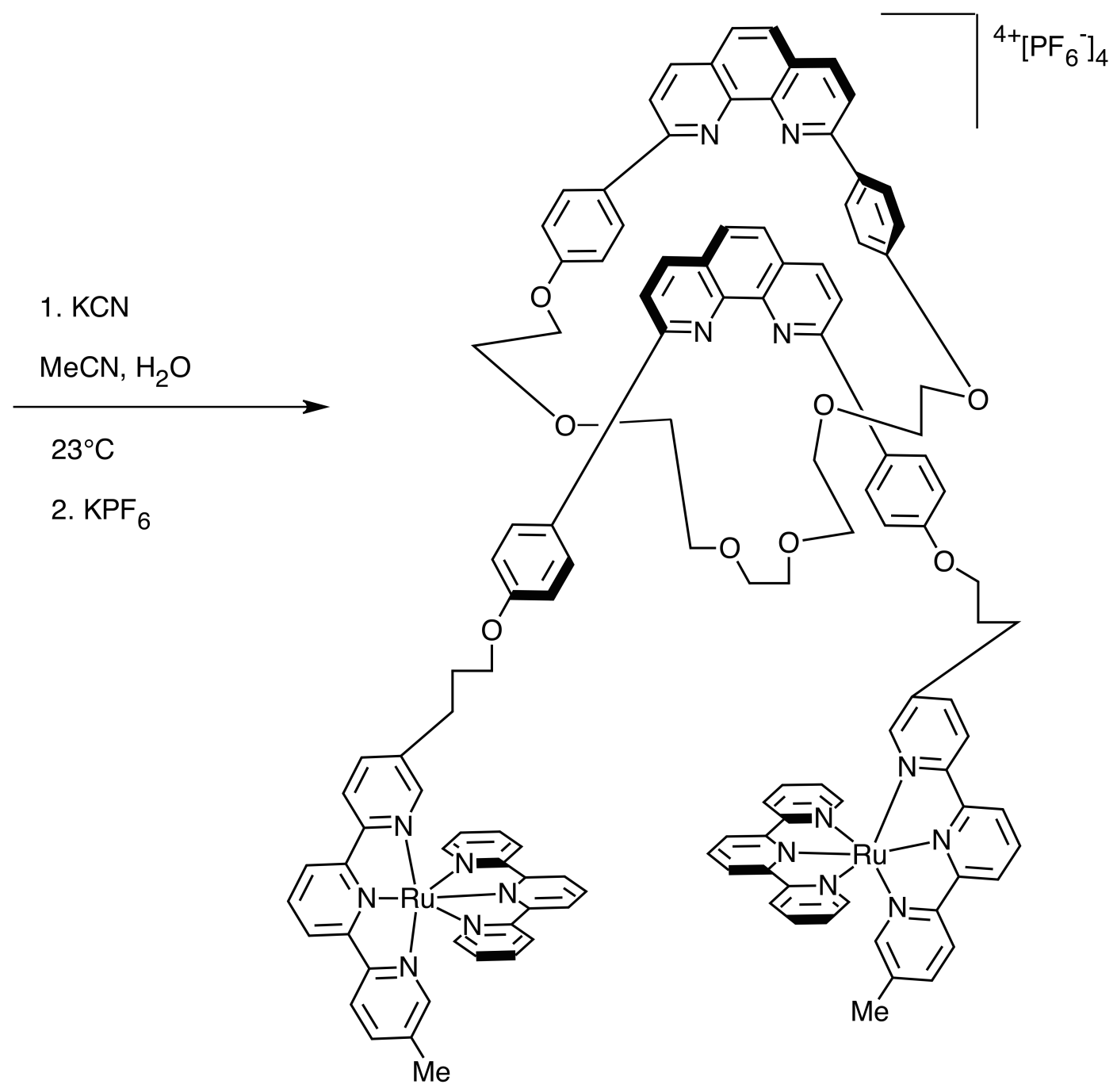

Figure 6. (a) - (c): Self-assembly of a rotaxane: (a) First step; (b) second step; (c) third step. 


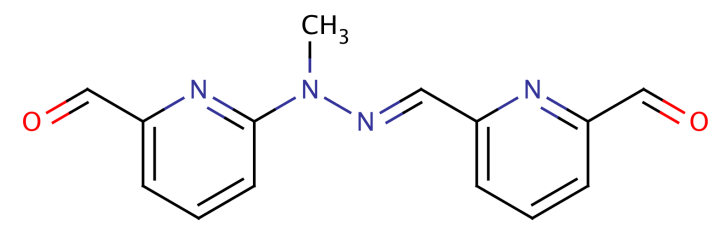

Figure 7. Ligand that switches shape from "W" to "U" when complexed with $\mathrm{Pb}(\mathrm{II})$.

A more recent concept in self-assembly that was explored by Lehn ${ }^{7}$ is shapeswitching of a ligand that occurs when the ligand is coordinated by a metal. One of the ligands created by Lehn et al. ${ }^{7}$ that exhibits shape-switching when coordinated by a metal is shown in Figure 7; it is (E)-6-((2-(6-formylpyridin-2-yl)-2methylhydrazono)methyl)-picolinaldehyde, and it is a derivative of pyridine-2carboxaldehyde-2'-pyridylhydrazone (PAPHY).

Lehn's group ${ }^{7}$ coordinated lead, zinc, and mercury to derivatives of pyridine-2carboxaldehyde-2'-pyridylhydrazone (PAPHY) and other nitrogenous ligands; all of these ligands changed shape upon coordination. The paper describes preparation of several different complexes in this way. Lehn $^{8}$ also through self-assembly, using the concept of shape-switching, formed an interesting set of complexes from a metal ion and a ligand termed "molecular tweezers." Zinc was a metal used for making these complexes; some of the complexes used the ligands depicted in Figure 8; the structure of the ligand coordinated to a metal ion is shown in Figure 9. 


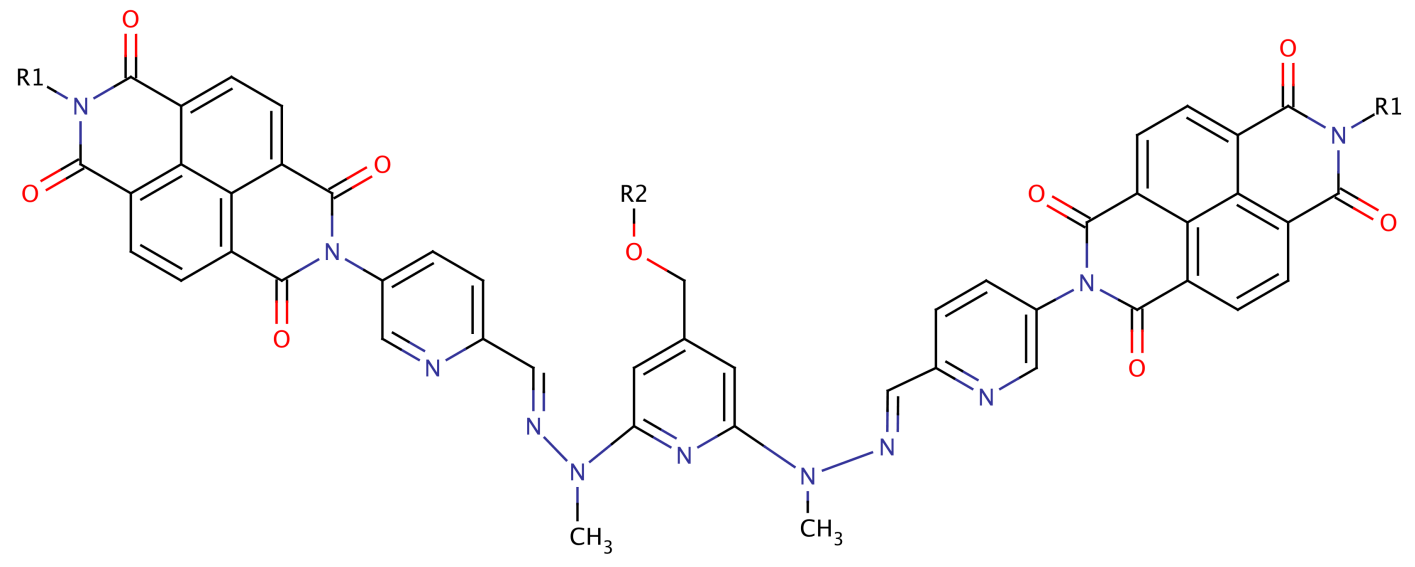

Figure 8. Ligand termed "molecular tweezers." R1 is n-butyl. R2 is either n-hexyl or 2-ethylhexyl.

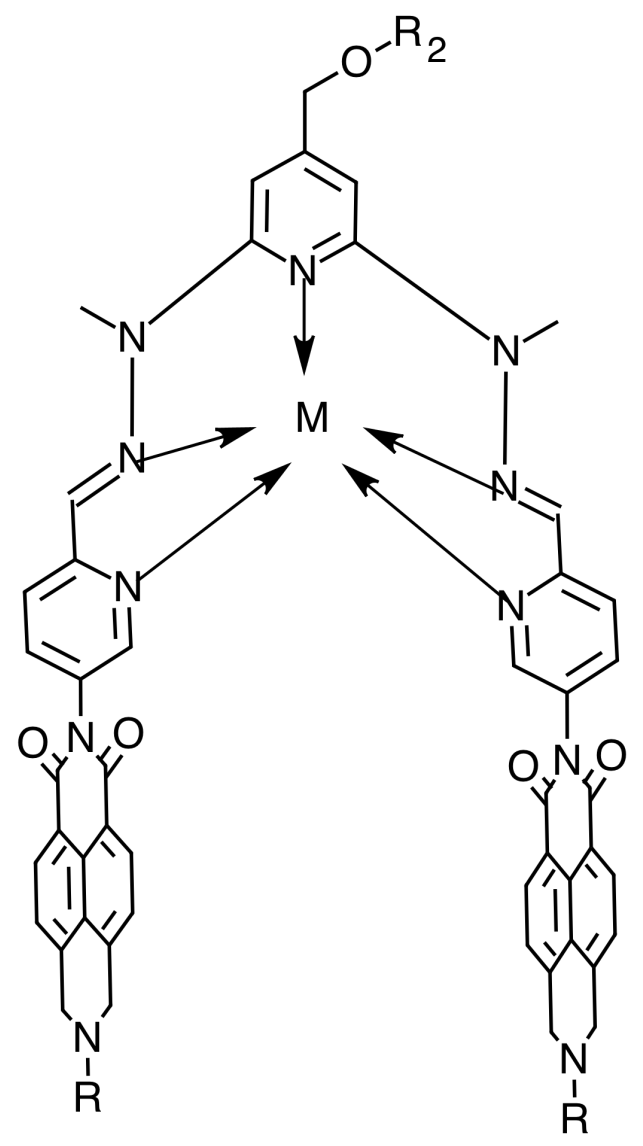

Figure 9. Ligand coordinated to a metal ion; the shape has changed from "W" to "U". 
Another configuration that can be assumed by a self-assembled complex is a grid. Jean-Marie Lehn and his colleagues ${ }^{9}$ coordinated polypyridyl ligands to transition metals resulting in grid complexes. One example of such a grid complex, in this case a $[2 \times 2]$ grid, is the complex shown in Figure 10; the metal ions at the four corners are either zinc(II) or cobalt(II).

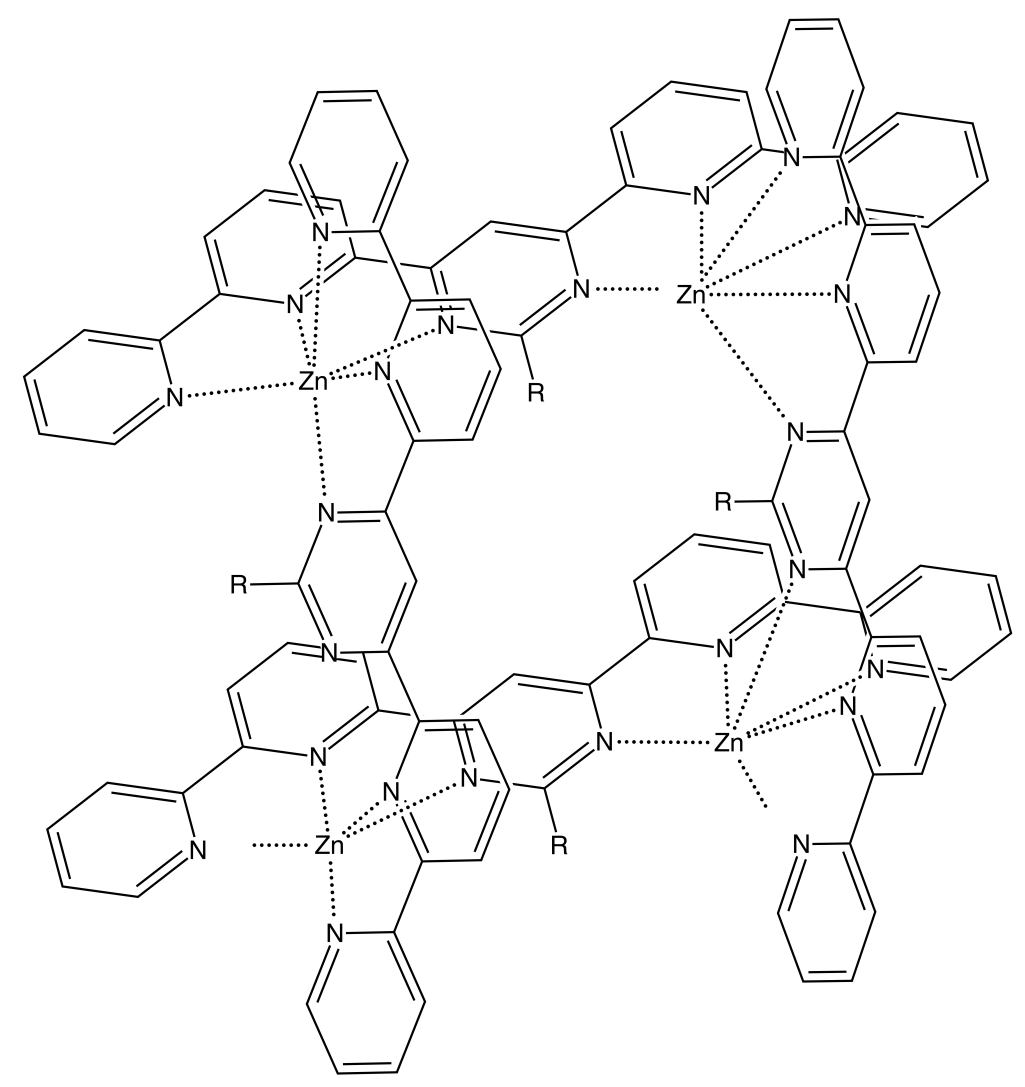

Figure 10. Grid complex. $R=$ phenyl or $p-\mathrm{C}_{6} \mathrm{H}_{4}-\mathrm{N}\left(\mathrm{CH}_{3}\right)_{2}$.

Another example of a grid complex formed by self-assembly from transition metal ions and polypyridyl ligands by Lehn ${ }^{10}$ is a $[2 \times 2]$ grid, shown in Figure 11, formed from four copper(I) ions and four copies of the ligand also depicted in Figure 11. 

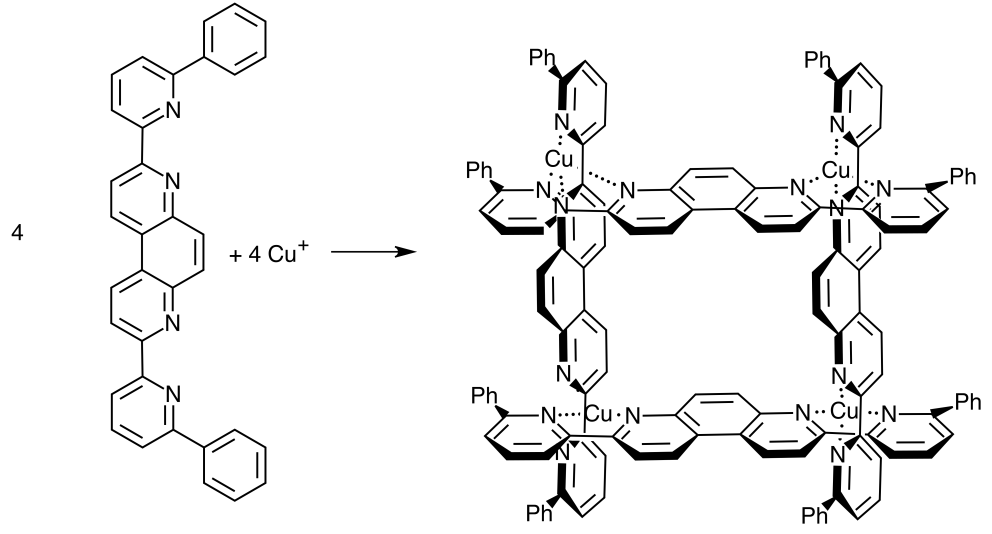

Figure 11. Self-assembly of copper(I) grid.

Brooker et al. ${ }^{11}$ also formed a [2×2] grid complex, shown in Figure 13, in this case using the macrocyclic ligand shown in Figure 12 and copper(I).

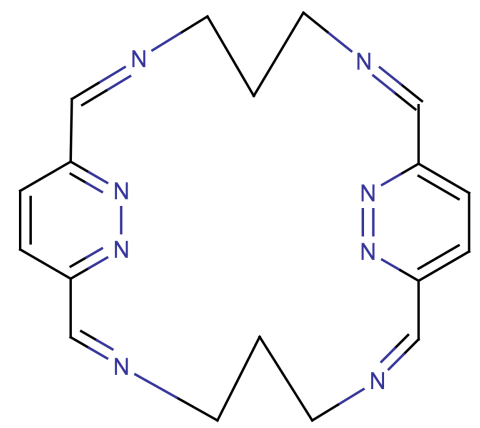

Figure 12. Macrocyclic ligand. 


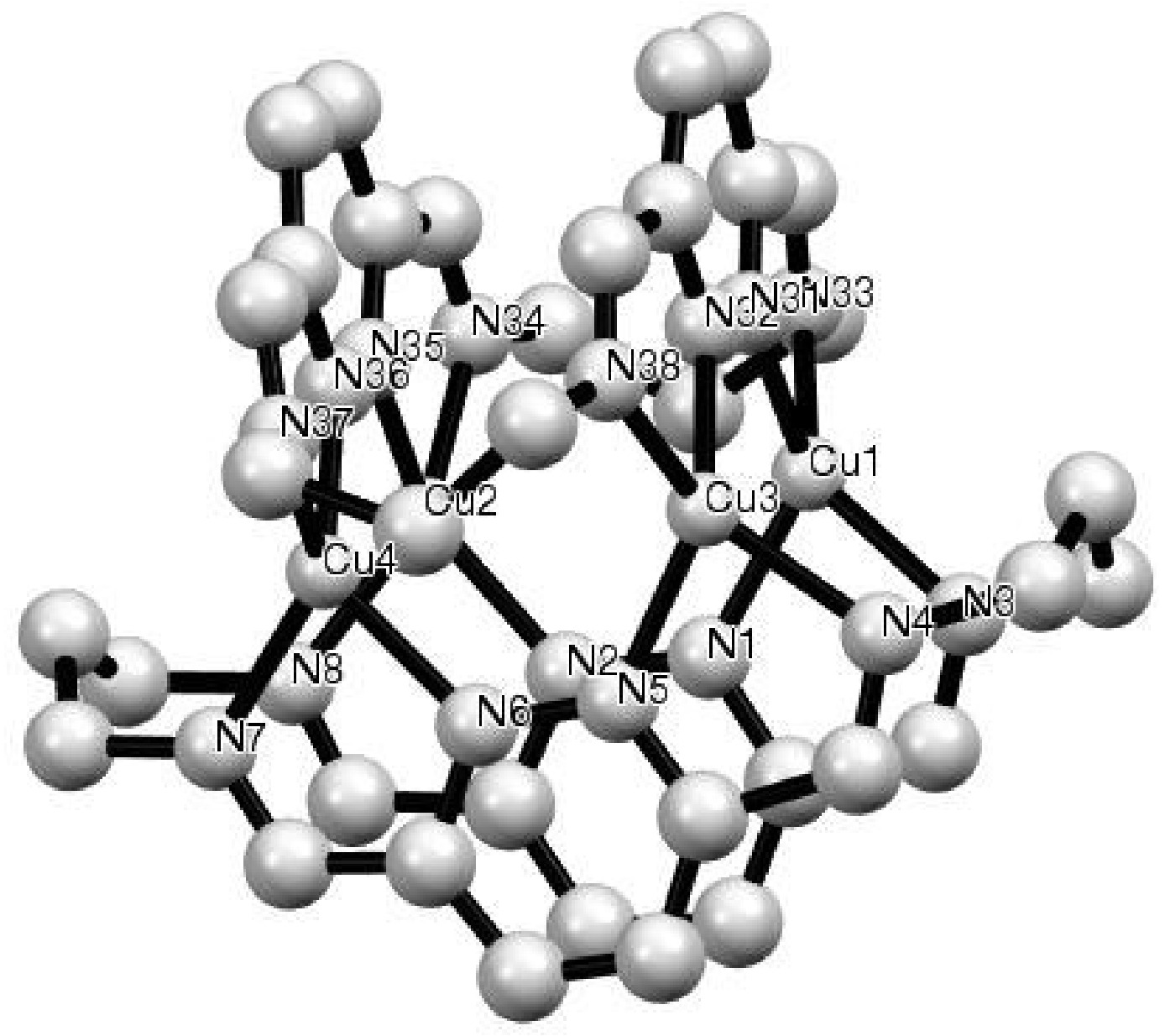

Figure 13. Grid complex formed from the macrocyclic ligand and copper(I), crystal structure. 
Lehn ${ }^{12}$ also created a $[3 \times 3]$ grid using silver(I) ions and another interesting ligand, 6,6'-bis[2-(6-methylpyridyl)]-3,3'-bipyridazine; the ligand is shown in Figure 14. The complex is shown in Figure 15.

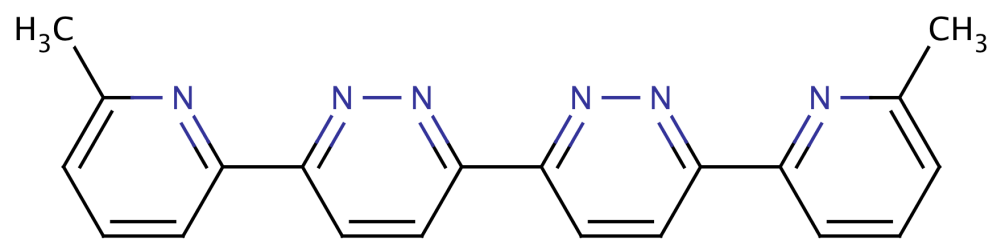

Figure 14. 6,6'-bis[2-(6-methylpyridyl)]-3,3'-bipyridazine.

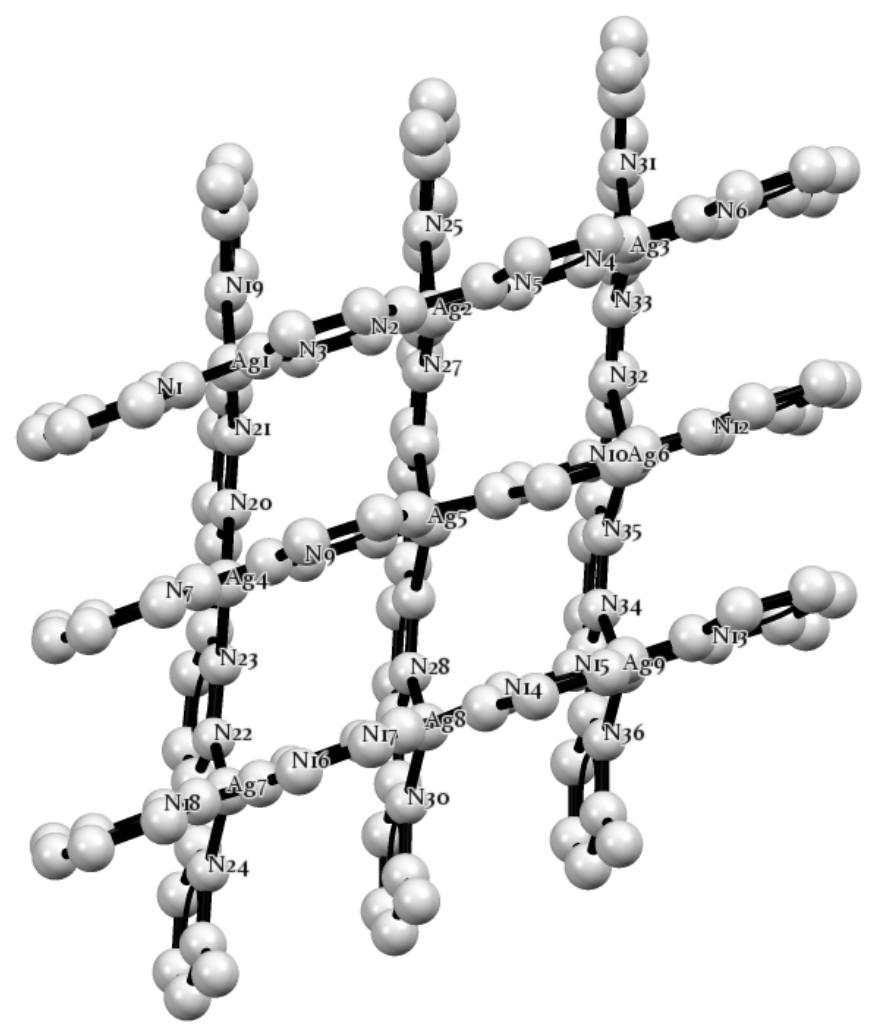

Figure 15. Crystal structure of $[3 \times 3]$ grid complex made with silver(I) and the ligand $6,6^{\prime}$-bis $[2$-(6-methylpyridyl)]-3,3'-bipyridazine. 
Zhao and co-workers ${ }^{13}$ also made a [3×3] grid complex using manganese(II) and the ligand 2POAP, which contains two kinds of heteroatoms, oxygen and nitrogen, in addition to its carbon and hydrogen atoms. The ligand is shown in Figure 16 and the complex is shown in Figure 17.<smiles>N/C(=N\N=C(/O)c1cccc(/C(O)=N/N=C(\N)c2ccccn2)n1)c1ccccn1</smiles>

Figure 16. 2POAP.

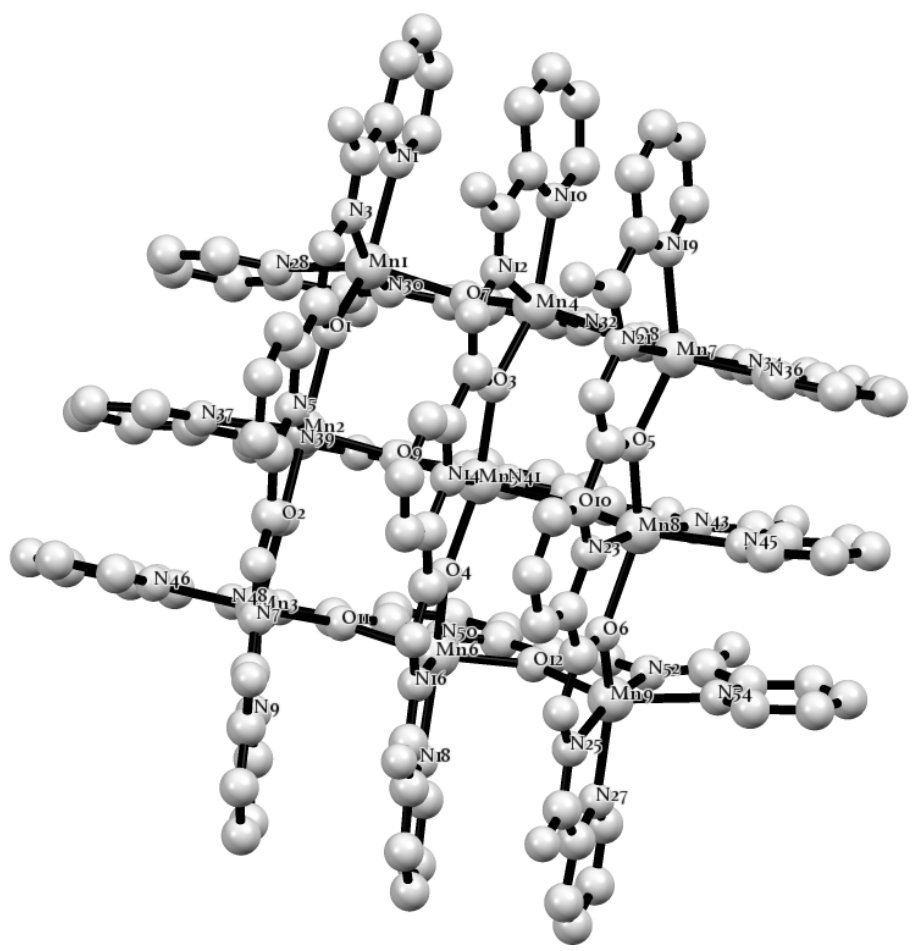

Figure 17. Crystal structure of $[3 \times 3]$ grid made from manganese(II) and $2 \mathrm{POAP}$. 
Groeneman and co-workers ${ }^{14}$ synthesized a rectangular grid with cobalt(II) ions with the formula $\left[\mathrm{Co}(\mathrm{pyz})(\right.$ terph $\left.)\left(\mathrm{H}_{2} \mathrm{O}\right)_{2}\right]$ that has holes that can each hold a pyrazine molecule, so that a self-assembled grid filled with pyrazine molecules forms from the component parts (Figure 18). This phenomenon of one complex having pores that can hold aromatic rings is known as "aromatic guest inclusion." 14 Groeneman's ${ }^{14}$ complex is an early example of a complex that can exhibit aromatic guest inclusion; the means for keeping the pyrazine molecules in place in this complex are hydrogen bonding and $\pi-\pi$ interactions. The possibilities for applications of this complex are many. For example, information could be stored in such a grid partly based on how many of the pores are filled by a pyrazine and in what pattern the pores are filled, such as in the case of exactly two of the pores of a $[3 \times 3]$ grid of this type being filled by pyrazine molecules.

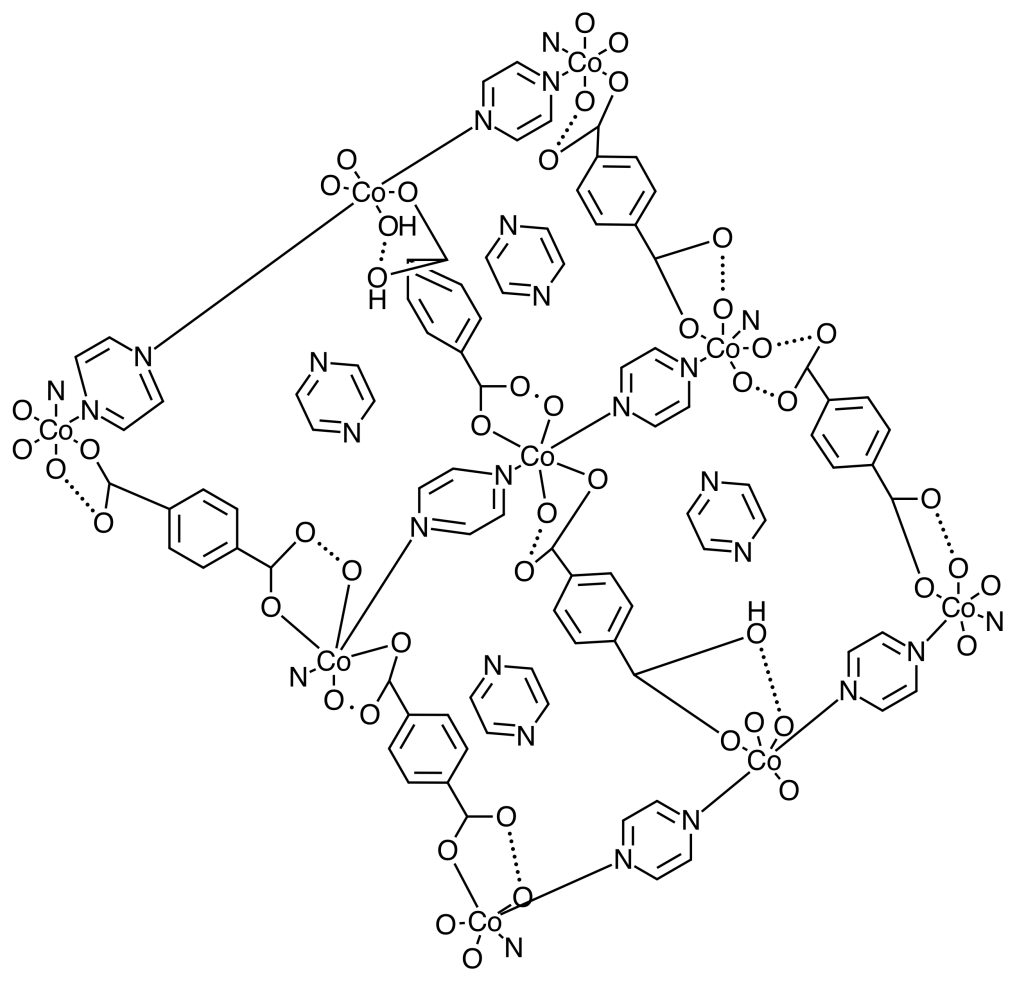

Figure 18. Grid complex with pyrazine rings filling the pores. 
The goal of many researchers is to use polypyridine ligands and transition metal ions as building blocks to form self-assembled grid complexes that may have applications as nanoscale electronic devices, with the various redox states of the transition metal centers being exploited for information-storage purposes. ${ }^{15}$ For example, Lehn et al. ${ }^{16}$ conducted redox chemistry with the cobalt(II) version of the grid complex shown in Figure 10, with $R$ being a phenyl group in this case. Cyclic voltammetry was performed on the complex, and a total of 10 different redox states were discovered. Table 1 displays the results of the cyclic voltammetry.

Table 1: Reduction potentials of the cobalt grid complex shown in Figure 10. The potentials are measured in reference to ferrocene.

\begin{tabular}{|c|c|c|c|c|c|c|c|c|c|c|c|}
\cline { 2 - 11 } \multicolumn{1}{c|}{} & \multicolumn{10}{c|}{ Reduction Step No. } \\
\hline & 1 & 2 & 3 & 4 & 5 & 6 & 7 & 8 & 9 & 10 & 11 \\
\hline$E[\mathrm{~V}]$ & -0.59 & -0.63 & -0.78 & -1.02 & -1.35 & -1.60 & -1.85 & -2.11 & -2.40 & -2.61 & -2.73 \\
\hline$\Delta E[\mathrm{~V}]$ & & 0.04 & 0.15 & 0.24 & 0.33 & 0.35 & 0.25 & 0.26 & 0.29 & 0.21 & 0.12 \\
\hline
\end{tabular}

Another form of a self-assembled complex is a rack complex; some early examples were achieved by Lehn's ${ }^{18}$ group in its synthesis of some rack complexes with ruthenium and polypyridyl ligands. These complexes are depicted in Figures 19 and 20. 


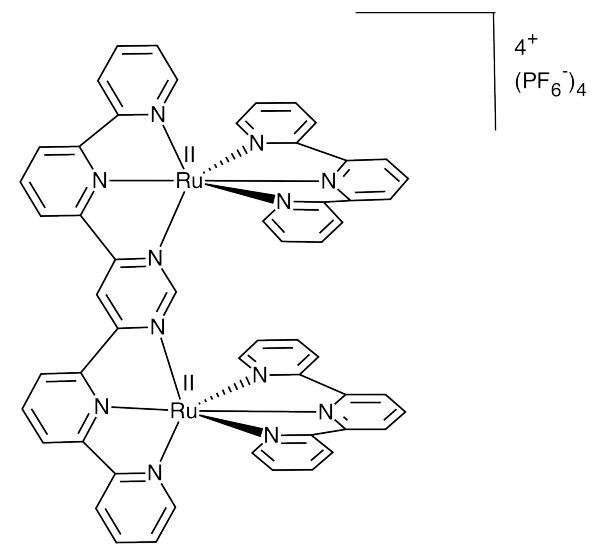

Figure 19. 2-tiered ruthenium rack self-assembled structure.

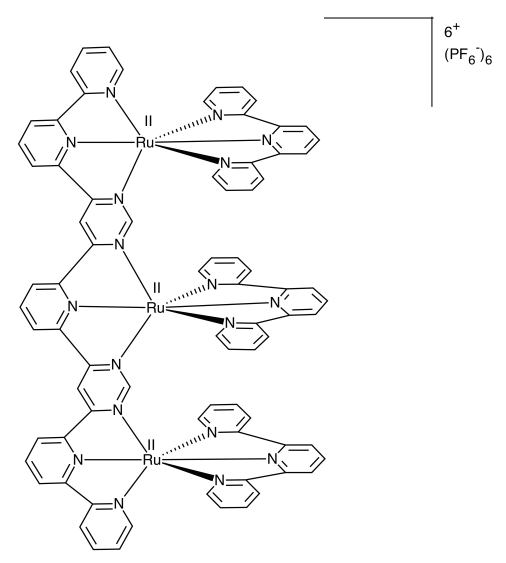

Figure 20. 3-tiered ruthenium rack self-assembled structure.

Coordination chemistry of free radicals has been investigated by various researchers. Sometimes the unpaired electrons in the ligands align with the unpaired electrons in transition metals used in these complexes, a condition known as ferromagnetism; other times the unpaired electrons in the ligands point in opposite directions from the unpaired electrons in the metals, a condition known as antiferromagnetism. Sometimes both of these phenomena can occur simultaneously in the same system in a condition known as ferrimagnetism; for example, a 
transition metal, free radical ligand polymer may alternate between ferromagnetic portions and antiferromagnetic portions. But in ferrimagnetic materials, the opposite spin alignments do not exactly cancel, so there is a net magnetic moment. $^{17}$

Some radical ligands are unstable and the resulting complexes can be easily oxidized or reduced so the ligands are in diamagnetic forms. In other words, the complexes of some radical ligands with metals have multiple oxidation states possible, such that in one or more of the oxidation states, the ligand is in paramagnetic form, while in other oxidation states, the ligand is in diamagnetic form. Other radical ligands are more stable, so that in the resulting complexes of these radicals with metals, the radical is in paramagnetic form in all oxidation states of the complex. Many complexes with radical ligands that can be easily oxidized or reduced have been created by Wieghardt. 19, 20, 23,24,26 For example, Wieghardt et al. ${ }^{19,20}$ synthesized complexes of copper, nickel, palladium, and cobalt with the $o$-iminobenzosemiquinonate radical and investigated these complexes by EPR and magnetic susceptibility. Figure 21 depicts the ligand o-iminobenzosemiquinonate radical. Figure 22 depicts one of the complexes, $\left[\mathrm{Co}{ }^{\mathrm{III}}\left(\mathrm{L}^{\mathrm{ISQ}}\right)_{3}\right]$, and Figure 23 depicts another of the complexes, $\left[\mathrm{Cu}^{\mathrm{II}}(\operatorname{dmtacn})\left(\mathrm{L}^{\mathrm{ISQ}}\right)^{1-}\right]$. The ground state of the complex $\left[\mathrm{Cu}^{\mathrm{II}}(\operatorname{dmtacn})\left(\mathrm{L}^{\mathrm{ISQ}}\right)^{1-}\right]$ is $S_{\text {total }}=1$ due to ferromagnetic coupling. 


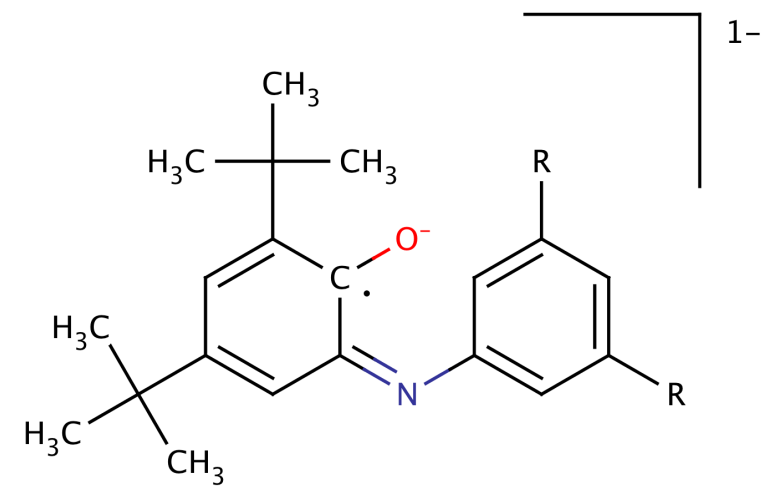

Figure 21. $o$-iminobenzosemiquinonate radical, $\left[\mathrm{L}^{\mathrm{ISQ}}\right]^{1-}$. 


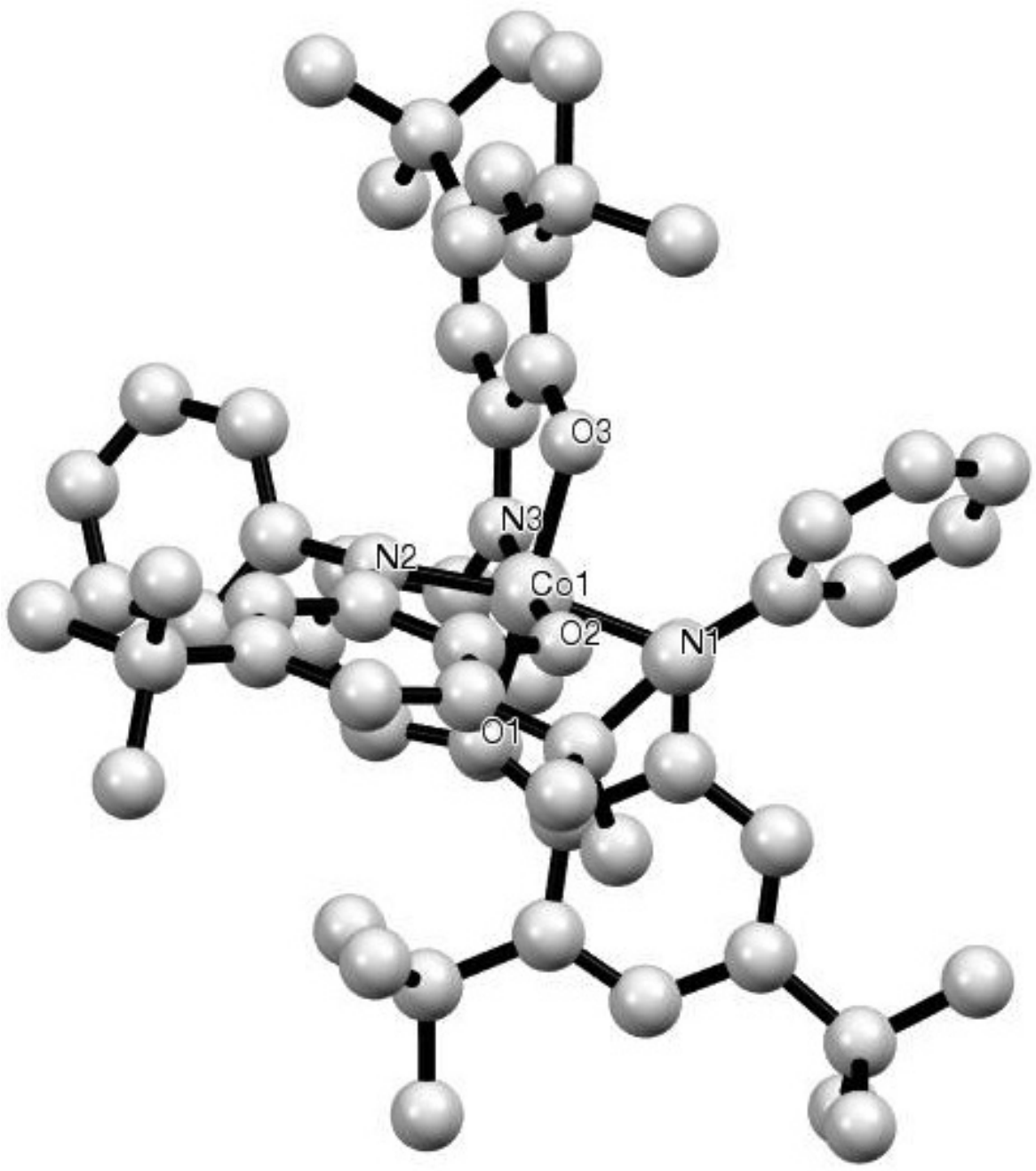

Figure 22. $\left[\mathrm{Co}^{\mathrm{III}}\left(\mathrm{L}^{\mathrm{ISQ}}\right)_{3}\right]$, X-ray crystal structure. 


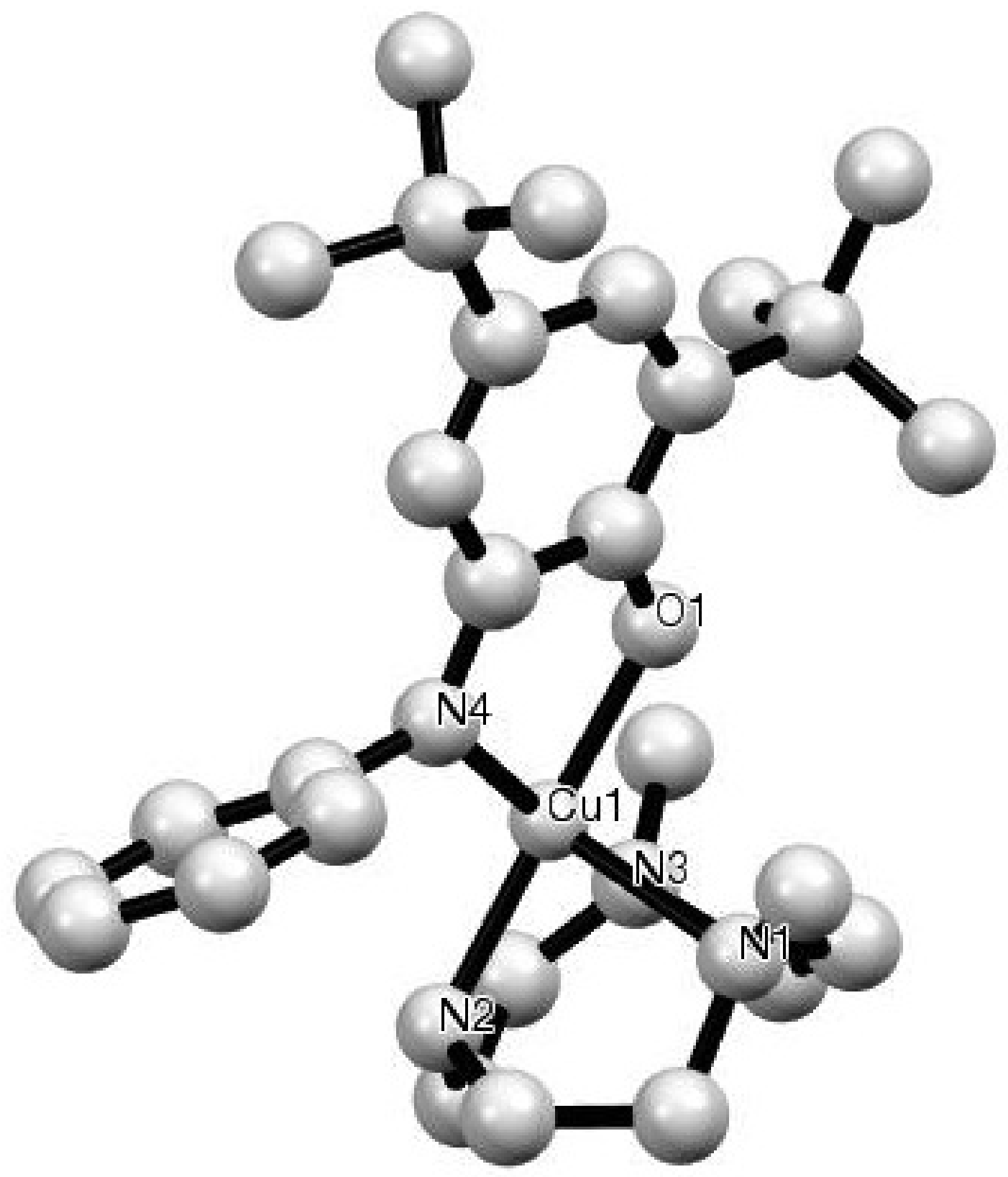

Figure 23. $\left[\mathrm{Cu}^{\mathrm{II}}(\operatorname{dmtacn})\left(\mathrm{L}^{\mathrm{ISQ}}\right)^{1-}\right]$; dmtacn $=1,4$-dimethyl-1,4,7-triazacyclononane.

Another example of the formation of a complex with unstable radical ligands is a complex constructed by Sieger and coworkers ${ }^{21}$ using $2,2^{\prime}$-bipyridine, which, along with pentamethyl cyclopentadiene, was coordinated to rhodium (Figure 24). The 
bipyridine became a radical in the reduced form of the complex. The same shift to a radical when the complex is reduced was observed with $2,2^{\prime}$-bipyrimidine as ligand in place of $2,2^{\prime}$-bipyridine and similarly with $2,2^{\prime}$-bipyrazine and $3,3^{\prime}$ bipyridazine. In this reduced form of each complex, rhodium is in the +1 oxidation state. EPR was used to study this complex, and the reduced form of the complex is shown in Figure 24. It is interesting because of "noninnocent" ligand behavior, which is when a redox-active ligand is coordinated to a metal and the oxidation states of the complex are unclear, so that more than one assignment of oxidation state to the ligand and to the coordinating metal ion is apparently possible according to Kaim et al. ${ }^{22}$ Sometimes the different oxidation assignments for a complex can be considered resonance forms because they have the same energy potential minimum, and other times the different oxidation assignments for a complex can be considered tautomeric forms in equilibrium where different forms have different energy potential minima. ${ }^{22}$ The various possible assignments of oxidation states of the ligand and metal for the $\mathrm{Rh}^{\mathrm{I}}$ complex are as follows: $\left[\left(\mathrm{N}^{\wedge} \mathrm{N}\right)\left(\mathrm{C}_{5} \mathrm{R}_{5}\right) \mathrm{Rh}^{0}\right] \longleftrightarrow\left[\left(\mathrm{N}^{\wedge} \mathrm{N}^{\bullet-}\right)\left(\mathrm{C}_{5} \mathrm{R}_{5}\right) \mathrm{Rh}^{\mathrm{I}}\right]$ $\longleftrightarrow\left[\left(\mathrm{N}^{\wedge} \mathrm{N}^{2-}\right)\left(\mathrm{C}_{5} \mathrm{R}_{5}\right) \mathrm{Rh}^{\mathrm{II}}\right]$, where $\mathrm{R}$ is either $\mathrm{H}$ or $\mathrm{CH}_{3}$.

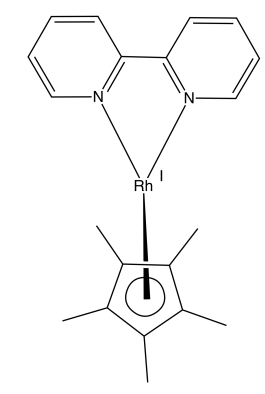

Figure 24. Reduced form of the 2,2'-bipyridineCp*Rh Complex; $\mathrm{Cp}^{*}=\eta^{5}-\mathrm{C}_{5} \mathrm{Me}_{5}$.

Yet another free-radical metal complex was synthesized by Wieghardt ${ }^{23}$ : an iron (II) complex with multiple different ligands, each with an ethylenediamine 
component, so that the iron binds to the two nitrogens. The radicals in this complex are also easily oxidized or reduced to diamagnetic forms. The generalized structure of these complexes is shown in Figure 25, and the ligands are illustrated in Figure 26.

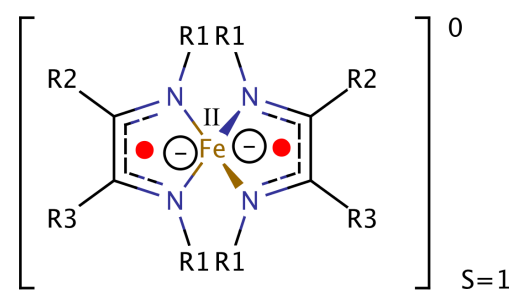

Figure 25. General structure of complexes of iron(II) with organic free radical ligands.

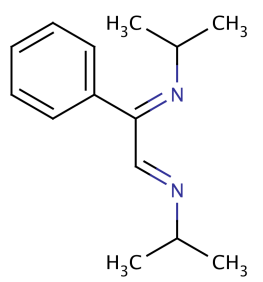

A

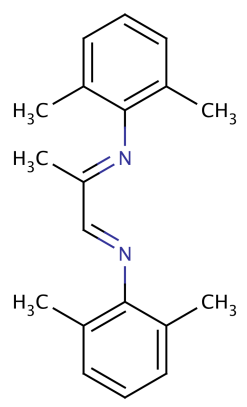

B

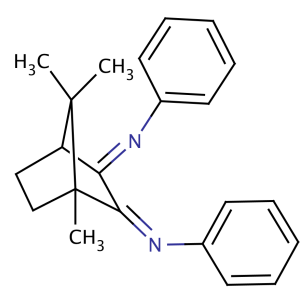

C

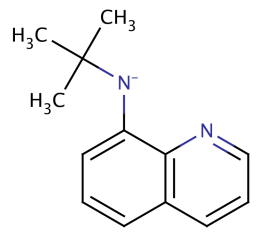

D

Figure 26. Ligands for iron (II) complexes.

The spin states for these complexes were determined. An example of a value for $S_{\text {total }}$ is 2 for $\left[\mathrm{Fe}^{\mathrm{II}}(\mathrm{A}) \mathrm{Cl}_{2}\right]$, where ligand A was in neutral form; however, when two copies of ligand A in monoradical form and zero chloride ions were coordinated to iron (II), the overall complex had $S_{\text {total }}=1 .{ }^{23}$ The same difference in spin quantum numbers was observed with ligand B as well. The complex consisting of the neutral form of the ligand B and iron (II) and two chloride ions had spin quantum number $S_{\text {total }}=2$. However, when the ligand B was in monoradical form, and the two chloride ions were removed, the complex had spin quantum number $S_{\text {total }}=1$. The 
iron was in a high spin $S=2$ state for all of these complexes, and in each of the complexes $\left[\mathrm{Fe}^{\mathrm{II}}\left(\mathrm{A}^{\cdot}\right)_{2}\right]$ and $\left[\mathrm{Fe}^{\mathrm{II}}\left(\mathrm{B}^{\cdot}\right)_{2}\right]$, where $\mathrm{A}^{\cdot}$ and $\mathrm{B}^{\cdot}$ denote ligand $\mathrm{A}$ in monoradical form and ligand B in monoradical form, respectively, there was antiferromagnetic coupling between the high-spin iron and the radical ligands, where each had a spin quantum number of $S=1 / 2$. Thus the overall complex has a spin quantum number of $S_{\text {total }}=1$.

Some complexes of molybdenum and tungsten with radical ligands were also prepared by Wieghardt et al. ${ }^{24}$; the ligands are shown below in Figure 27. Wieghardt ${ }^{24}$ determined that the complex $\left[\mathrm{Mo}^{\mathrm{V}}\left(\mathrm{L}_{N, S}\right)_{2}\left(\mathrm{~L}_{N, S}\right)\right]^{0} \cdot\left(\mathrm{C}_{2} \mathrm{H}_{5}\right) \mathrm{O}$ has a spin state of $\mathrm{S}=0$.

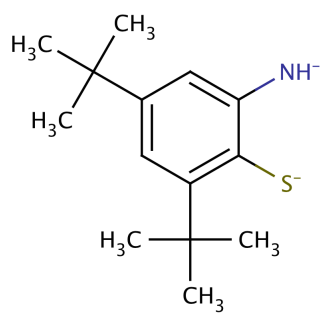

$\left(\mathrm{L}_{\mathrm{N}, \mathrm{s}}\right)^{2-}$<smiles>Nc1ccccc1F</smiles>
$(a b t)^{2-}$

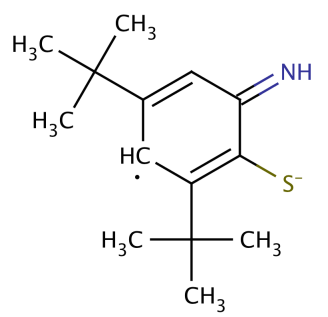

$\left(\mathrm{L}_{N, S}^{0}\right)^{1-}$

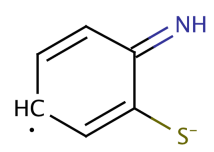

$\left(\mathrm{abt}^{0}\right)^{1-}$

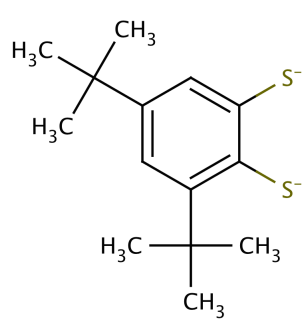

$\left(\mathrm{L}_{\mathrm{s}, \mathrm{S}}\right)^{2-}$<smiles>Fc1ccccc1S</smiles>

(bdt) ${ }^{2-}$<smiles>CC(C)(C)c1cc(F)c(S)c(C(C)(C)C)c1</smiles><smiles>Sc1ccccc1S</smiles>

$\left(b^{\bullet}\right)^{1-}$

Figure 27. Ligands for molybdenum and tungsten complexes.

Nickel complexes of some ligands with some benzene rings and nitrogens and oxygens that can adopt a radical form were synthesized by Rotthaus et $a l^{25}$. Figure 28 shows the ligands used along with a nickel complex of one of the ligands, $\mathrm{L}^{1}$. 

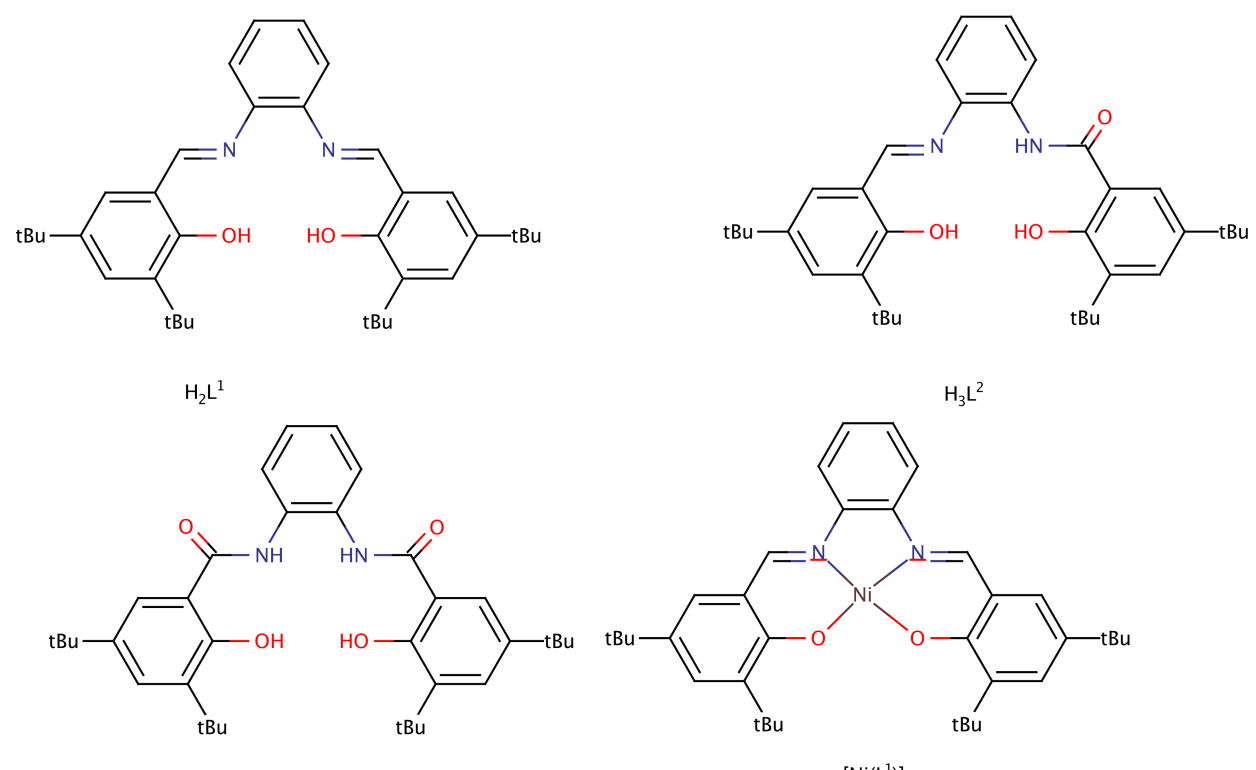

$\mathrm{H}_{4} \mathrm{~L}^{3}$

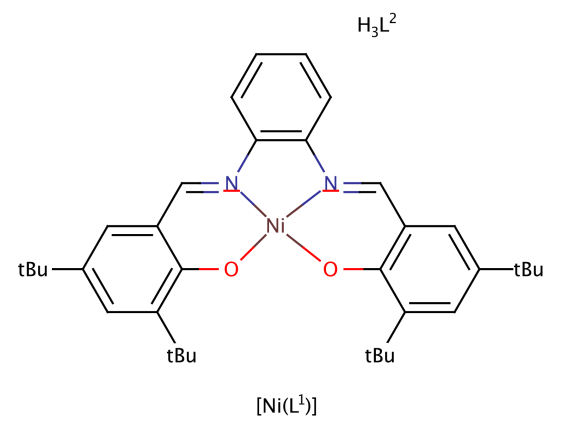

Figure 28. Ligands that can adopt a radical form, along with a nickel complex of one of them.

EPR was used to investigate the radical forms of the complexes; from the EPR spectrum, it was observed that the complex $\left[\mathrm{Ni}\left(\mathrm{L}^{1}\right)\right]^{+}$has a radical ligand and that the unpaired electron is partly delocalized onto the nickel $d$ orbitals. ${ }^{25}$

Wieghardt et al. ${ }^{26}$ also investigated nickel, palladium, and platinum complexes of some o-diiminobenzosemiquinonato(1-) radical ligands. Figure 29 depicts the ligands, while Figure 30 depicts the general form of one of the metal complexes. For this particular complex, $\mathrm{S}_{\text {total }}=0$. 


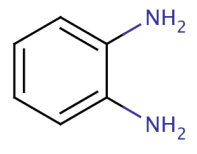
$\mathrm{H}_{2}\left[\mathrm{~L}^{\mathrm{PD}}\right]$<smiles>Nc1ccccc1N</smiles>
$\left(\mathrm{L}^{\mathrm{PDI}}\right)^{2-}$

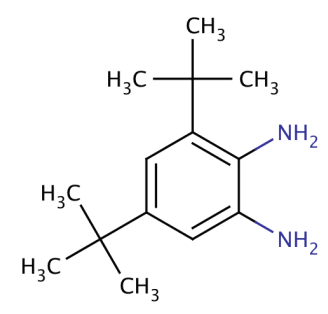

$\left.\mathrm{H}_{2}{ }^{2} L^{\mathrm{PD}}\right]$

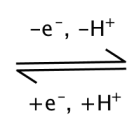<smiles>N=c1cccc[c-]1N</smiles>

$\left(L^{\mid S Q}\right)^{1-}$<smiles>Nc1ccccc1Nc1ccccc1</smiles>

$\mathrm{H}_{2}\left[{ }^{3} \mathrm{LPl}^{\mathrm{PD}}\right]$

Figure 29. Ligands for $\mathrm{Ni}, \mathrm{Pd}, \mathrm{Pt}$ complexes.

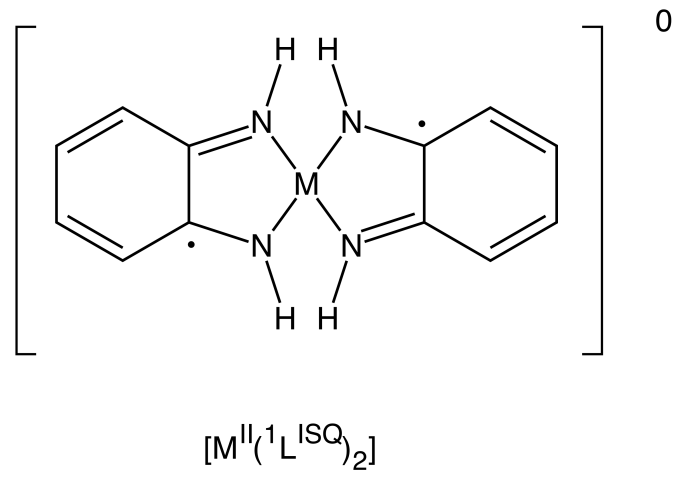

Figure 30. Complex of a metal with $\mathrm{L}^{I S Q}$ ligand. $M$ is either $\mathrm{Ni}, \mathrm{Pd}$, or Pt.

An early example of a nitronyl nitroxide coordination complex with first row transition metal ions is a manganese(II) complex that was prepared by Caneschi et $a l .{ }^{27}$ with NITiPr and hfac, where hfac is hexafluoroacetylacetonate and NITiPR is 2-isopropyl-4,4,5,5-tetramethyl-4,5-dihydro-1H-imidazolyl-1-oxyl 3-oxide; the ligand for this complex is shown in Figure 31. Its formula is $\mathrm{Mn}(\mathrm{hfac})_{2} \mathrm{NIT}-i$-Pr. ${ }^{27}$ This was found to have ferrimagnetic properties. Chains of manganese(II) complexes were also formed by Caneschi ${ }^{29}$ and co-workers; these are useful as magnetic 
materials. These chains are linked by the nitronyl nitroxide radicals and exhibit ferrimagnetic or even mildly ferromagnetic properties.

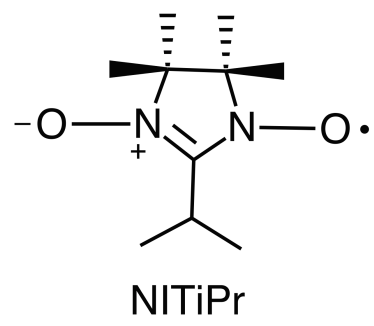

Figure 31. Nitronyl nitroxide ligand for $\mathrm{Mn}(\mathrm{II})$ complex.

An early example of a nitronyl nitroxide coordination complex with lanthanide ions is the complex $\mathrm{Gd}(\mathrm{hfac}){ }_{3} \mathrm{NITiPr}{ }^{28}$ This complex forms chains, with each chain consisting of Gd(III) ions linked by nitronyl nitroxide radicals, in particular by the oxygens of the radicals. ${ }^{28}$ ESR studies indicated that at low temperature, next-nearest neighbor interactions are predominant in these chains. Modeling of magnetic data for these systems indicated a two-spins-up, two-spins-down configuration at low temperature; the spin states of $\mathrm{Gd}(\mathrm{III})$ and the nitronyl nitroxide radical, being $S=7 / 2$ and $S=1 / 2$, respectively, were uncorrelated at room temperature, but became correlated at low temperature as indicated by the decrease in $\chi T$ corresponding to decreased temperature. ${ }^{28} \chi T$ is the product of the magnetic susceptibility $\chi$ and the temperature $T$ in Kelvin. The magnetic susceptibility $\chi$ is equal to the magnetization inside a material divided by the applied magnetization; it does not have units.

Both manganese(II) and nickel(II) complexes with an NIT2Py ligand were formed by Luneau et $a l^{30}$ (Figure 33); the ligand is shown in Figure 32. Strong antiferromagnetic coupling was observed in these complexes. The signs of magnetic exchange were negative for both complexes, which is another way of stating that 
the complexes showed antiferromagnetism, or at least is consistent with the complexes being antiferromagnetic. The nickel(II) complex showed a singlet ground state.

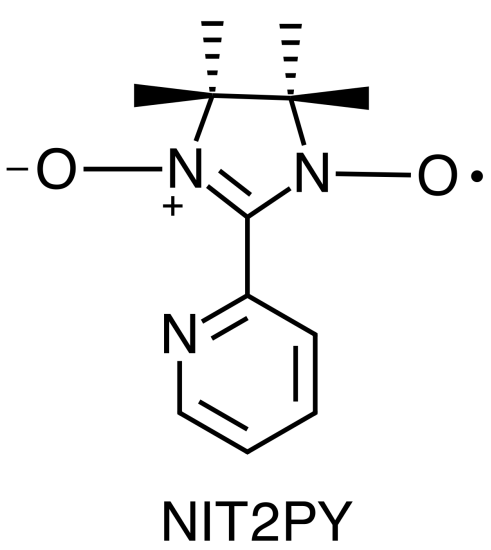

Figure 32. 2-2-pyridyl nitronyl nitroxide ligand for $\mathrm{Mn}(\mathrm{II})$ and $\mathrm{Ni}(\mathrm{II})$ complexes. 


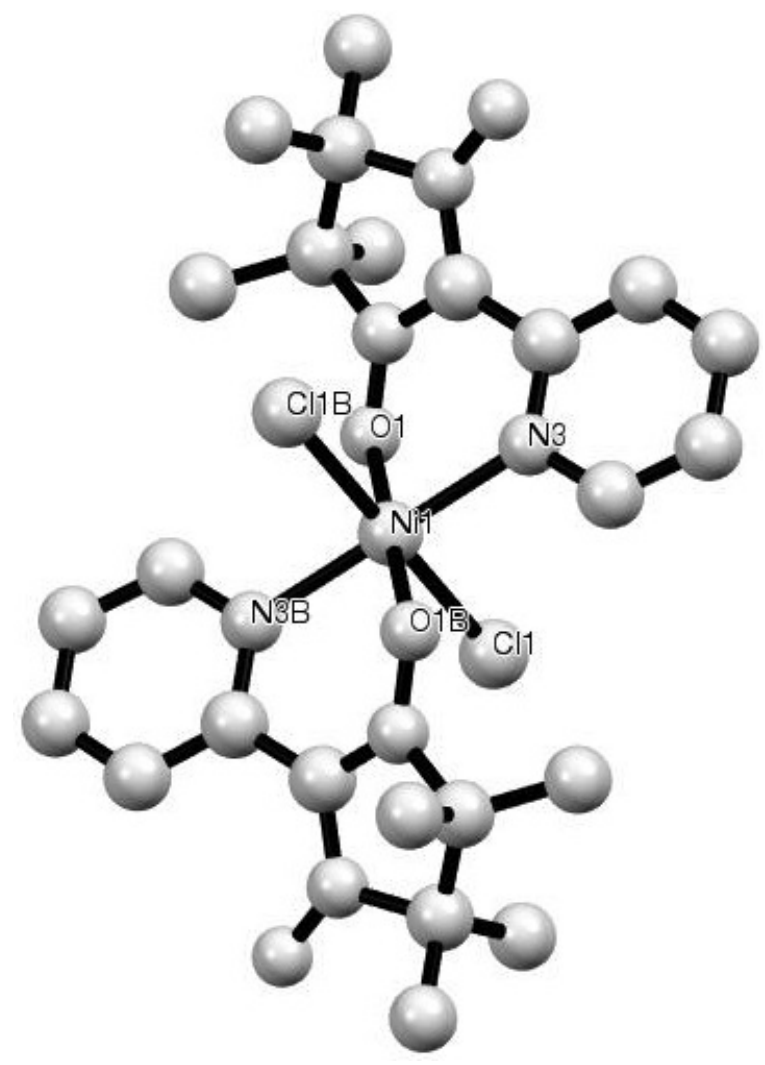

Figure 33. Nickel nitronyl nitroxide complex, X-ray crystal structure.

Another example of a nitronyl nitroxide coordination complex was reported by Wang $^{31}$ who formed $\mathrm{Mn}(\mathrm{II})$ and $\mathrm{Co}(\mathrm{II})$ complexes of 2-(4-quinolyl)nitronyl nitroxide ligands; the $\mathrm{Mn}(\mathrm{II})$ complex is shown in Figure 34. 


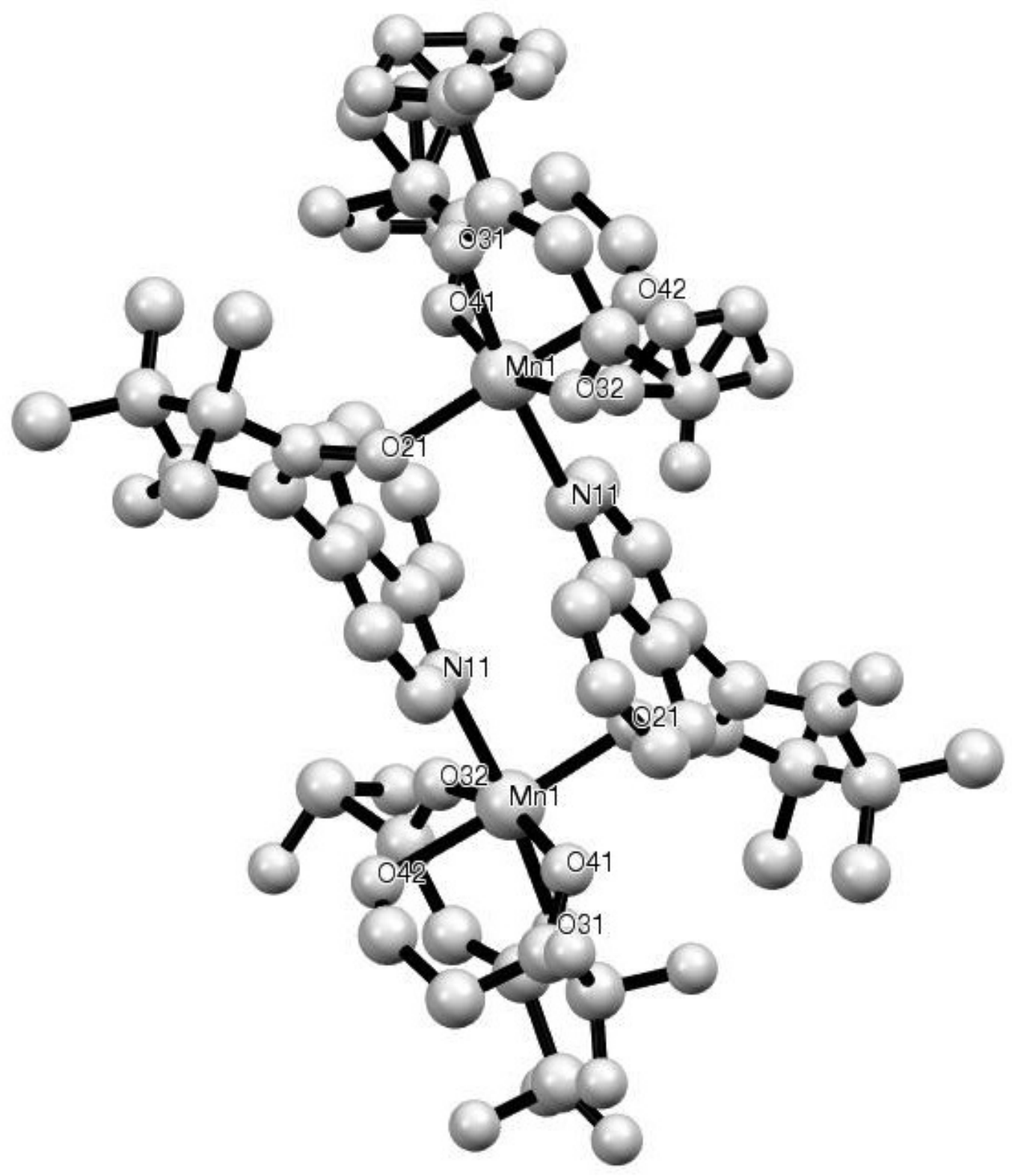

Figure 34. 4-QNNN Mn(II) complex, X-ray crystal structure.

In what are the first examples of self-assembled grid complexes containing free radical ligands, a pair of $[2 \times 2]$ grid complexes of a nitronyl nitroxide radical ligand, a diamagnetic amidino oxide ligand, and $\mathrm{Cu}$ II were prepared by researchers Shuvaev et al. ${ }^{32}$. The formula for one of two grids prepared is 
$\left(\mathrm{L}_{n i t}\right)_{2}(\mathrm{~L})_{2} \mathrm{Cu}(\mathrm{II})_{4}\left(\mathrm{BF}_{4}\right)_{4} \cdot \mathrm{CH}_{3} \mathrm{OH}$. The formula for the other grid is $\left(\mathrm{L}_{n i t}\right)_{0.5}(\mathrm{~L})_{3.5} \mathrm{Cu}(\mathrm{II})_{4}\left(\mathrm{BF}_{4}\right)_{4} \cdot \mathrm{CH}_{3} \mathrm{OH}$. The nitronyl nitroxide ligand they used, $\mathrm{L}_{n i t}$, is depicted in Figure 35, and the complex $\left(\mathrm{L}_{n i t}\right)_{2}(\mathrm{~L})_{2} \mathrm{Cu}(\mathrm{II})_{4}\left(\mathrm{BF}_{4}\right)_{4} \cdot \mathrm{CH}_{3} \mathrm{OH}$ is depicted in Figure 36. The grid complex $\left(\mathrm{L}_{n i t}\right)_{2}(\mathrm{~L})_{2} \mathrm{Cu}(\mathrm{II})_{4}\left(\mathrm{BF}_{4}\right)_{4} \cdot \mathrm{CH}_{3} \mathrm{OH}$ displayed some mixture of ferromagnetism and antiferromagnetism, while the complex $\left(\mathrm{L}_{n i t}\right)_{0.5}(\mathrm{~L})_{3.5} \mathrm{Cu}(\mathrm{II})_{4}\left(\mathrm{BF}_{4}\right)_{4} \cdot \mathrm{CH}_{3} \mathrm{OH}$ showed ferromagnetic coupling. ${ }^{32}$

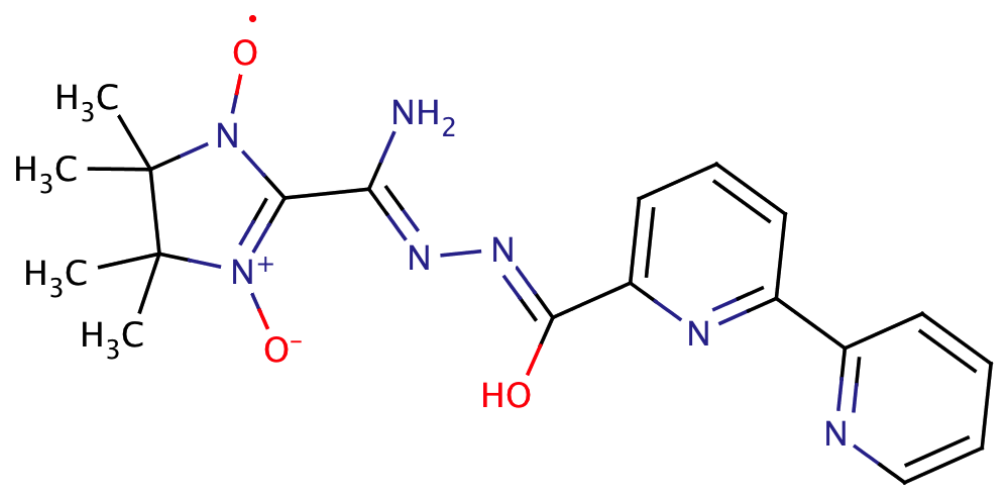

Figure 35. HLnit, the nitronyl nitroxide ligand used for the $[2 \times 2]$ grid complex with $\mathrm{Cu}(\mathrm{II})$ 


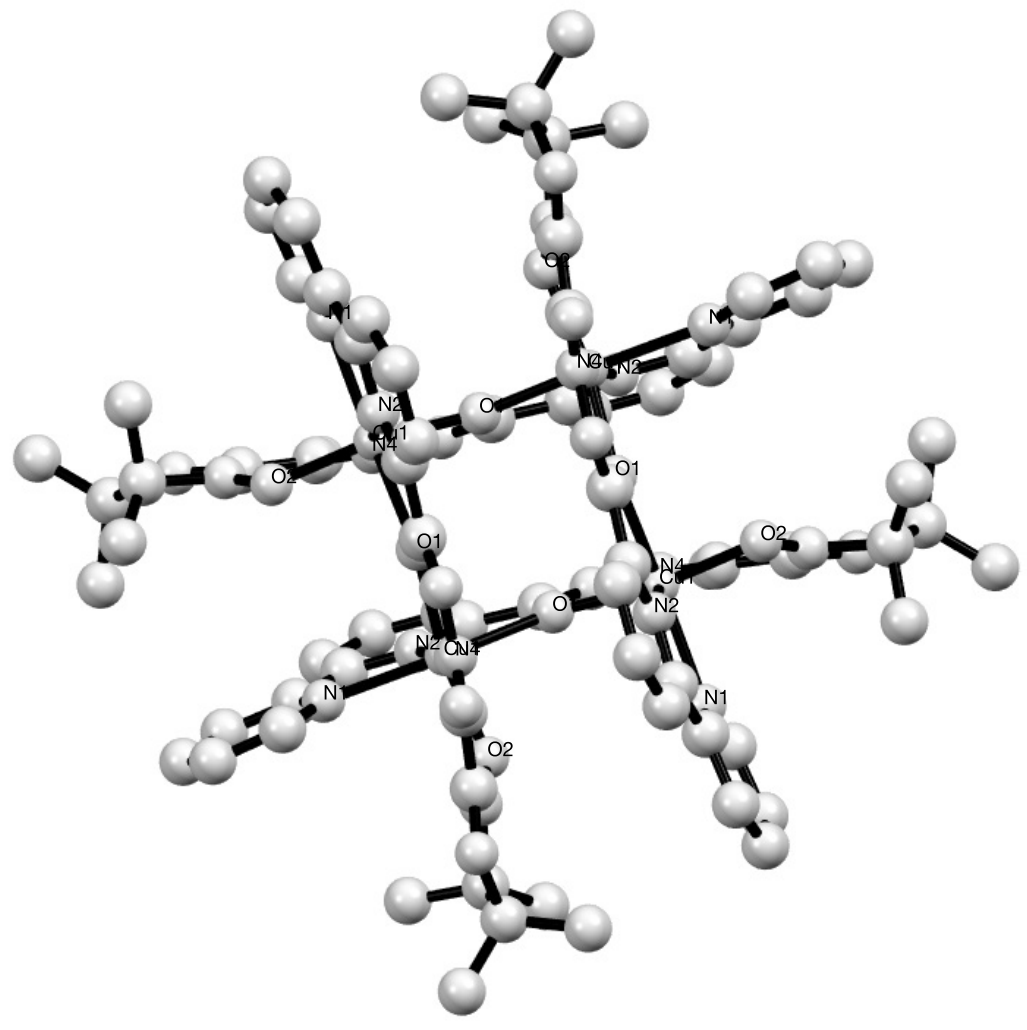

Figure 36. Copper(II) grid complex of the HLnit ligand, X-ray crystal structure.

Verdazyls are relatively stable nitrogenous radicals that were first synthesized by Kuhn and Trischmann ${ }^{33}$ in 1963 by methylation and oxidation of triphenylformazan (Figure 37). 
<smiles>c1ccc(/N=N/C(=N/Nc2ccccc2)c2ccccc2)cc1</smiles>

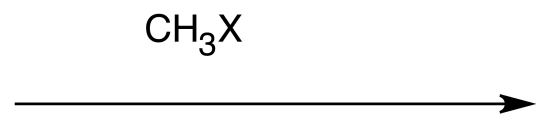<smiles>CN(/N=C(/N=N/c1ccccc1)c1ccccc1)c1ccccc1</smiles>
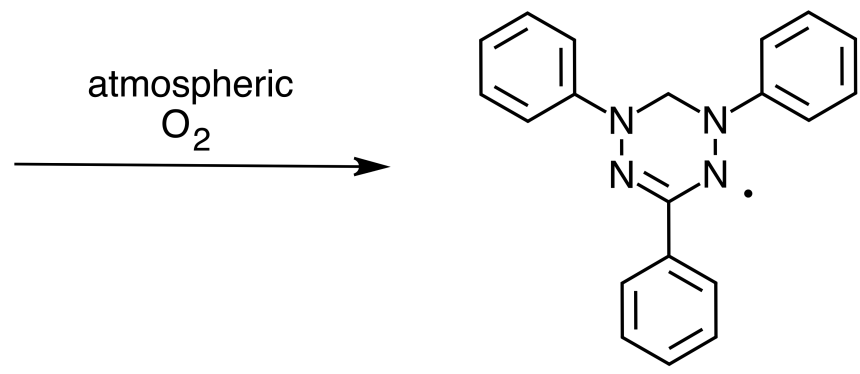

Figure 37. First reported synthesis of a verdazyl

In 1980, Neugebauer ${ }^{34}$ reported having synthesized the first 6-oxoverdazyl (Figure 38).

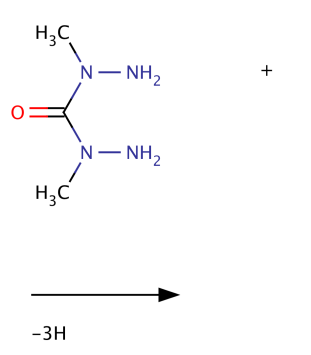

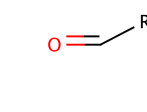

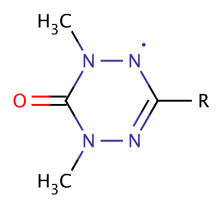

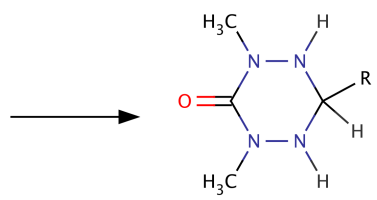

(a) $\mathrm{R}=\mathrm{H}$

(b) $\mathrm{R}=\mathrm{C}_{6} \mathrm{H}_{5}$

Figure 38. First reported synthesis of a 6-oxoverdazyl.

Verdazyls themselves are poor ligands; they do not coordinate to metals strongly enough. It is necessary to make verdazyls look like bipyridine to enhance their coordination. Robin Hicks' research group ${ }^{35,36}$ synthesized 6-oxoverdazyls with functional groups attached that make them resemble terpyridines and 
experimented with formation of grid complexes through self-assembly via coordination to transition metals. The terpyridine analog verdazyl that Hicks coordinated to $\mathrm{Ni}(\mathrm{II})$ and other transition metals in the $2+$ oxidation state is shown in Figure 39. In particular, the other metals used were $\mathrm{Zn}, \mathrm{Mn}$, and $\mathrm{Cu}$, all in the $2+$ oxidation state.

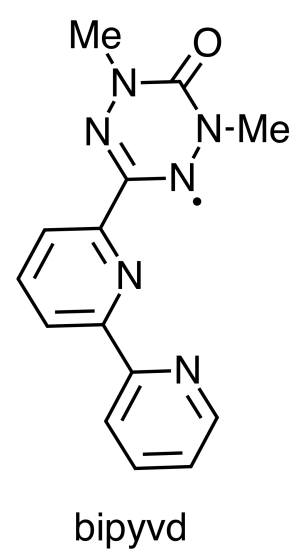

Figure 39. Terpyridine analog verdazyl, bipyvd.

However the bond distance from the metal to the verdazyl nitrogen was longer than the bond distances from the metal to the pyridine nitrogens. ${ }^{36}$ The methyl groups interfered with coordination, so this ligand did not bind strongly. ${ }^{36}$ Similar ditopic verdazyl ligands with the terminal ring(s) being verdazyl(s) first synthesized by Hicks 10 years ago have only been reported to form one complex with a metal, reported in 2006, and it is not a self-assembled complex; thus it is probable that such ligands do not self-assemble. ${ }^{37}$

The Hicks group ${ }^{38}$ also determined singlet-triplet energy gap values for verdazyls linked through benzene using variable temperature ESR and/or magnetic susceptibility experiments. These molecules are shown in Figure 40. 

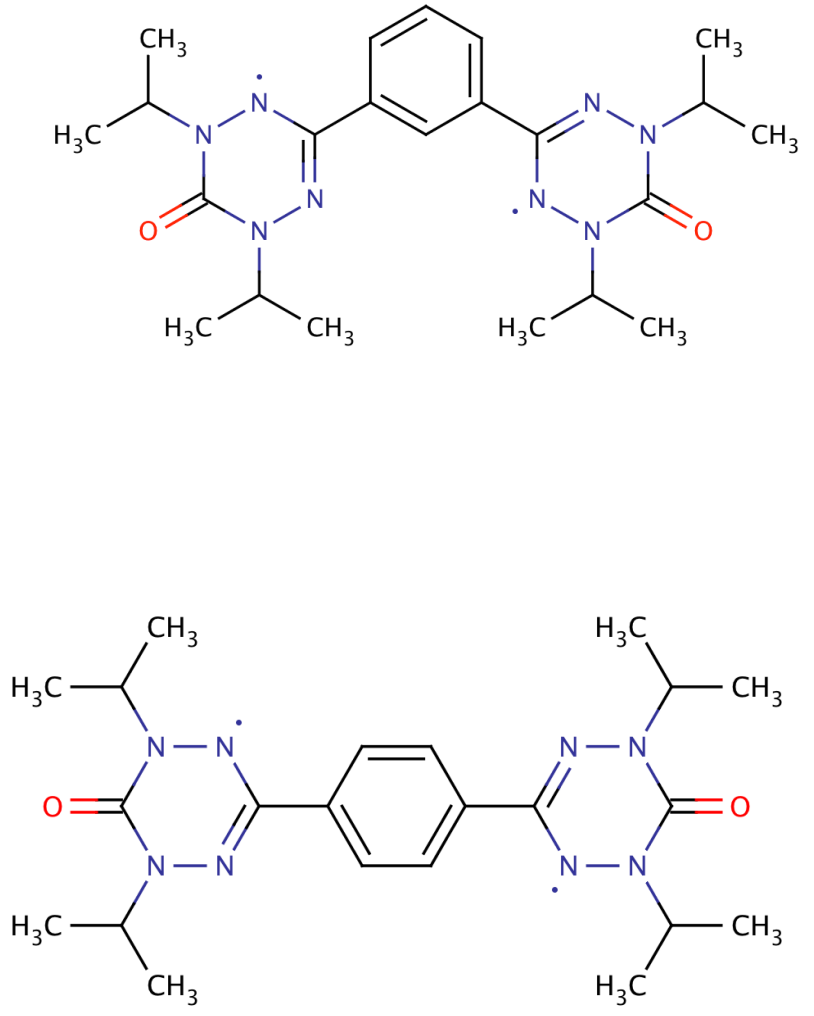

Figure 40. Benzene-bridged verdazyls.

For example, the singlet-triplet energy separation J value for the parabenzene-bridged verdazyl shown above is $\mathrm{J}=-30.3 \mathrm{~cm}^{-1} .38$

Brook et al. ${ }^{39}$ reported the first complex of verdazyl ligands with a metal; the metal used was a transition metal in the +1 oxidation state. In particular, Brook et 
$a l .{ }^{39}$ reported preparation of bisverdazyl copper(I) complexes in which halides acted as bridging ligands (Figure 41).

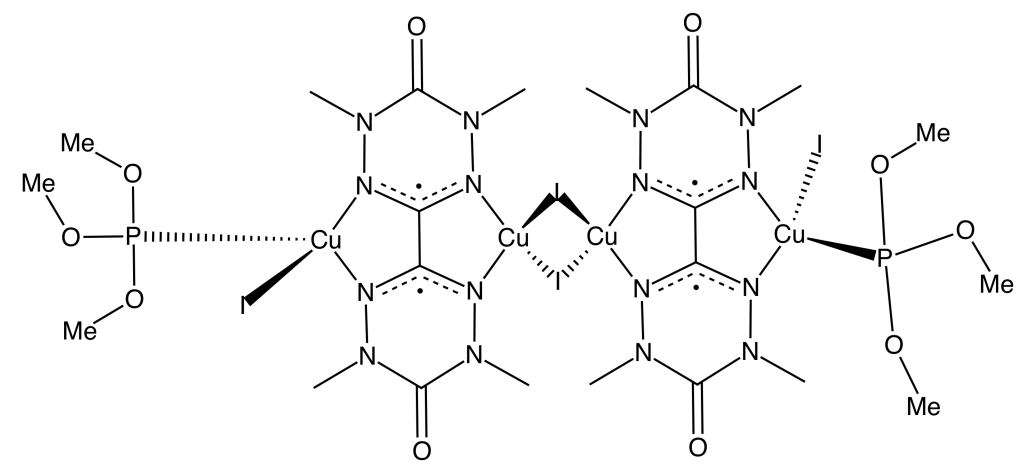

Figure 41. Bisverdazyl copper(I) complex with iodide as a bridging ligand.

Another verdazyl copper(I) complex was synthesized by Brook et al ${ }^{40}$ and reported in 2000. This complex also makes use of halides as bridging ligands, similar to the one in Figure $41 .{ }^{39}$ Figure 42 shows this complex.

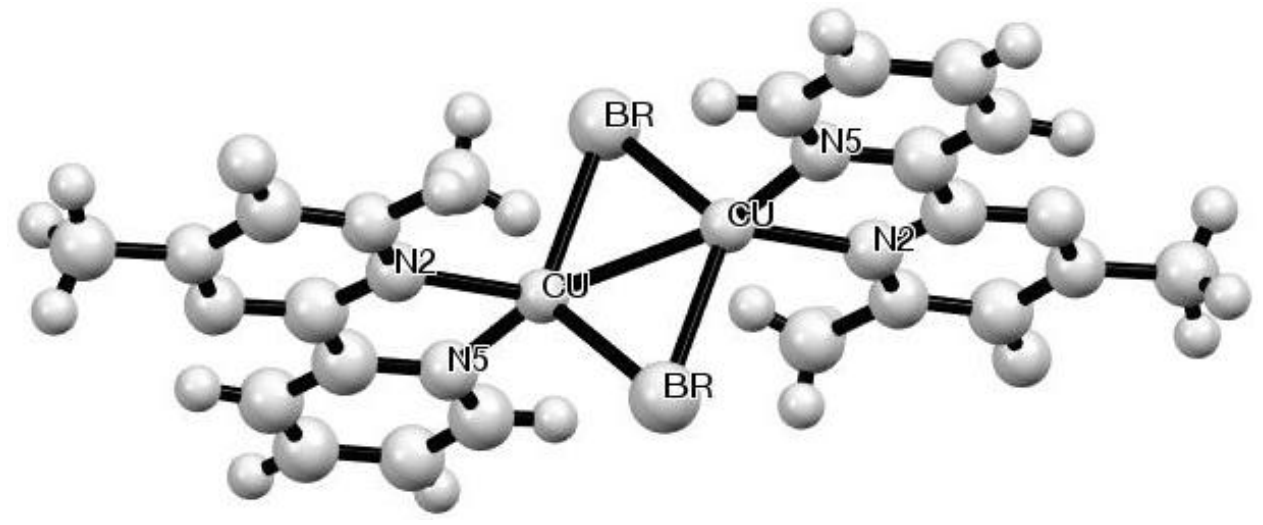

Figure 42. Verdazyl copper(I) complex with bromides as bridging ligands, X-ray crystal structure.

Furthermore, the Hicks ${ }^{39-41,43}$ group synthesized the first copper(I) verdazyl complex that does not include halides as bridging ligands: the $\mathrm{Cu}(\mathrm{I})$ complex with two monoradical verdazyls represented in Figure 43. 


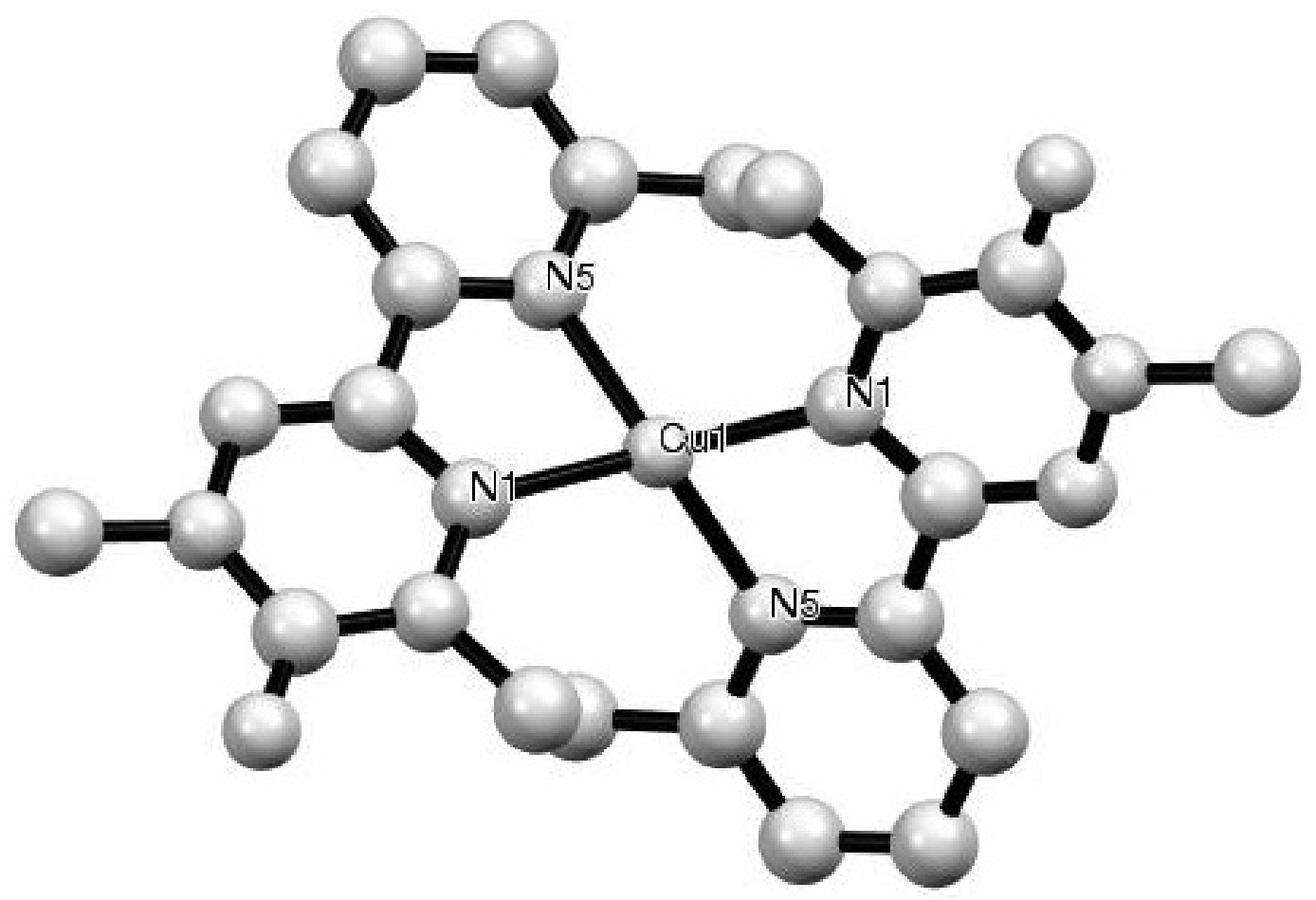

Figure 43. Verdazyl copper(I) complex, X-ray crystal structure.

Brook $^{44}$ and co-workers synthesized a verdazyl copper(I) complex which, like Hicks' $2001 \mathrm{Cu}(\mathrm{I})$ complex, does not include halides as bridging ligands. The verdazyl monoradical ligands each have a few attached isopropyl groups; the complex is shown in Figure $44 .^{44}$ 


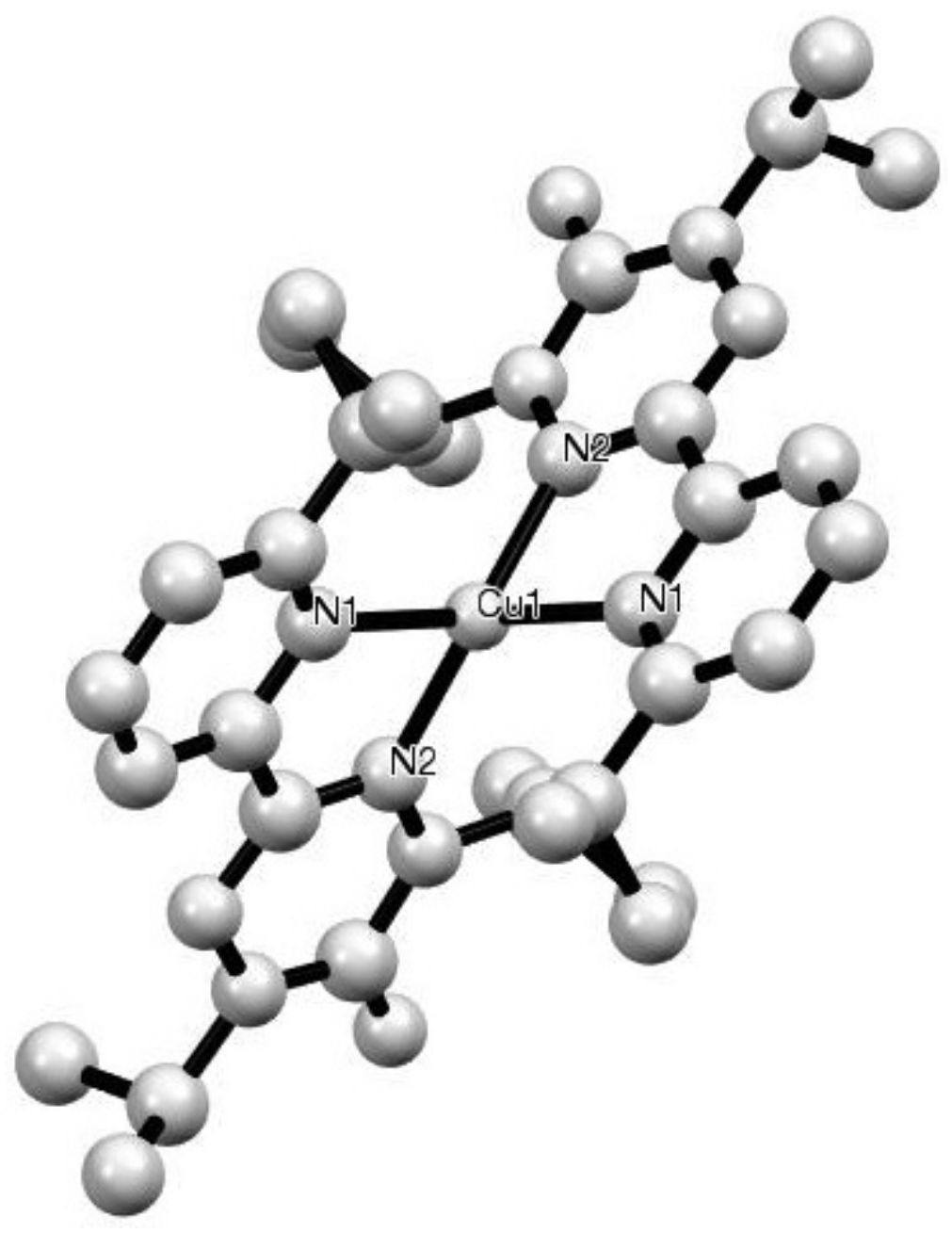

Figure 44. X-ray crystal structure of verdazyl copper(I) complex, in which isopropyl groups are attached to the verdazyl.

In an effort to make verdazyls look more like the terpyridine ligands used by Lehn for self-assembly, Brook et al. ${ }^{42}$ synthesized a 6-oxoverdazyl ligand from pyridine-2-carboxaldehyde-2'-pyridylhydrazone. Unlike the earlier verdazyl bipyridine complexes synthesized by Hicks ${ }^{35,36}$, the verdazyl was the middle ring of this three ring terpyridine analog ligand. This solved the problem of the methyl groups getting in the way of coordination. A complex was formed of this monoradical 6-oxoverdazyl and nickel(II). ${ }^{42}$ Figure 45 shows the verdazyl ligand, 
while Figure 46 shows the X-ray crystal structure of the complex. Magnetic susceptibility measurements indicated this complex had strong ferromagnetic coupling between the nickel(II) and the verdazyl ligands. Similar ferromagnetic coupling was observed in the Hicks ${ }^{35} \mathrm{Ni}$ (II) verdazyl bipyridine complex reported in 2000.

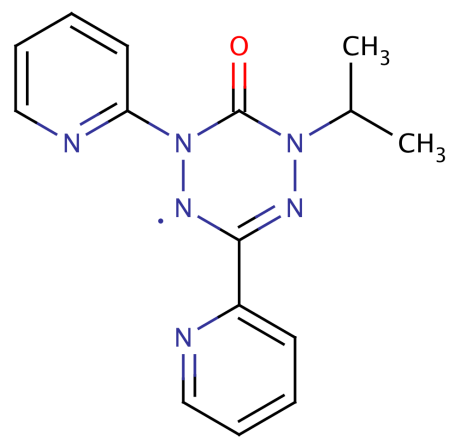

Figure 45. 1,5-dipyridylverdazyl. 


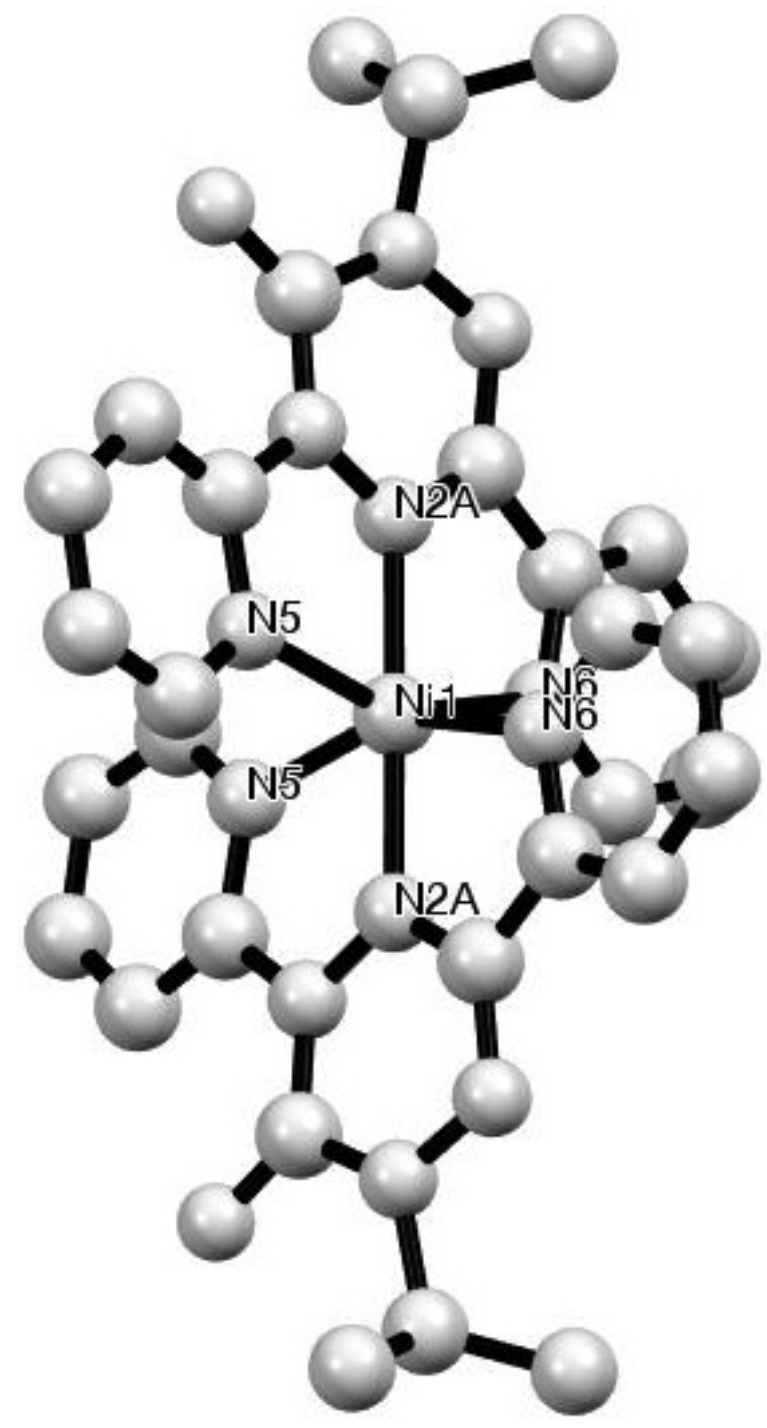

Figure 46. Nickel(II) complex of 1,5-dipyridylverdazyl, X-ray crystal structure. 
In the present project, a ditopic bis-6-oxoverdazyl ligand, which is a diradical, shown in Figure 47, is coordinated with nickel(II) in order potentially to form a self-assembling grid complex.

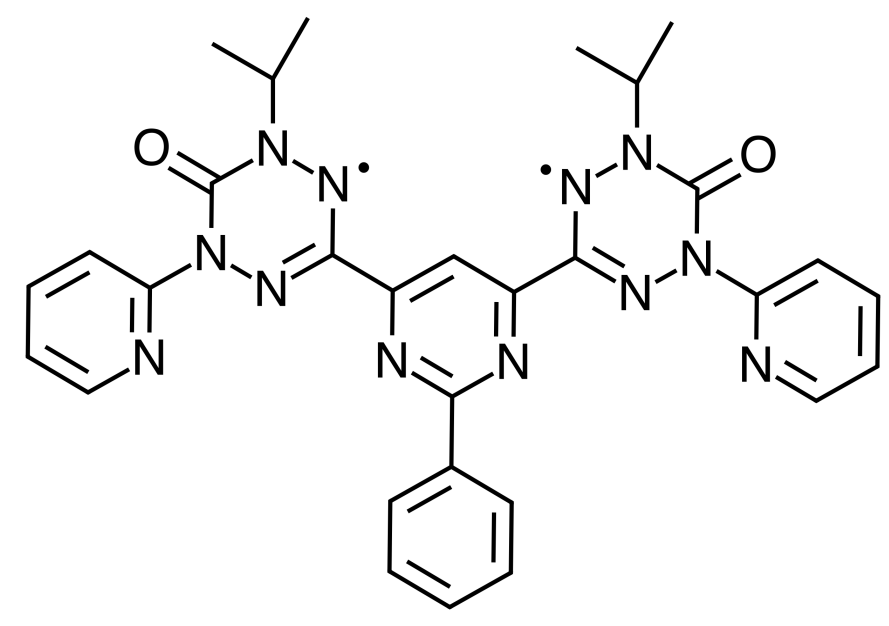

Figure 47. Ditopic bis-verdazyl ligand.

\section{EXPERIMENTAL PROCEDURES}

\section{General}

Most experiments were performed in a fume hood. Solvents were used without purification. Triethylamine was distilled from calcium hydride before use. ${ }^{1} \mathrm{H}$ NMR spectra were recorded at $300 \mathrm{MHz}$ and ${ }^{13} \mathrm{C}$ NMR spectra were recorded at 75.4 MHz on a Varian Mercury300 instrument. For all NMR spectra, chemical shifts were determined using solvent peaks as a reference. The IR spectra were recorded as thin films on $\mathrm{NaCl}$ plates using a Mattson Genesis II FTIR. Electrospray Mass Spectra were recorded using a PE SCIEX API300 LC/MS/MS system and a Turbo Ionspray. The model ID of the API300 is 076907. EPR spectra were recorded using a Bruker EMX X-band instrument. 


\section{Synthesis of 4,6-dimethyl-2-phenyl pyrimidine}

This compound was prepared by reacting acetylacetone with benzamidine as reported by Haley and Maitland. ${ }^{45}$ NMR shows that this is 4,6-dimethyl-2-phenyl pyrimidine. ${ }^{1} \mathrm{H}$ NMR $\mathrm{CDCl}_{3} \delta$, ppm: $8.48(\mathrm{~m}), 7.44(\mathrm{~m}), 6.71(\mathrm{~s}), 2.42$ (d).

\section{Synthesis of 2-phenyl pyrimidine 4,6-dicarboxaldehyde}

This compound was prepared by selenium dioxide oxidation of 4,6-dimethyl-2-phenyl pyrimidine as reported by Dutta et al. ${ }^{46}{ }^{1} \mathrm{H} \mathrm{NMR}^{-C^{2} l_{3}} \delta$, ppm: 9.93 (s), 8.42 (d), 8.40 (d), 8.39 (d), 8.34 (d), 8.32 (d), 7.90 (s), 7.38 (d), 7.36 (d), $7.33(\mathrm{~d}), 3.49$ (s).

\section{Synthesis of 2-phenyl-pyrimidine-4,6-dicarbaldehyde bis(2-pyridyl}

\section{hydrazone)}

This compound was prepared by reacting 2-phenyl pyrimidine 4,6-dicarboxaldehyde with two equivalents of 2-hydrazinopyridine as reported by Barbiou et al. ${ }^{47}{ }^{1} \mathrm{H}$ NMR DMSO $\delta$, ppm: 11.63 (s), 8.40 (m), 8.20 (d), 8.15 (s), $8.09(\mathrm{~s}), 7.78(\mathrm{t}), 7.54(\mathrm{t}), 7.42(\mathrm{~d}), 6.90(\mathrm{t})$.

\section{Synthesis of} (E)- $\{[(\{[($ tert-butoxy $)$ carbonyl $]$ amino $\}$ (propan-2-yl)amino)carbonyl $]$ (pyridin-2-yl)amino $\}(\{6-[(1 \mathrm{E})-(\{[(\{[$ tert-butoxy $)$ carbonyl $]$ amino $\}$ (propan-2-yl)amino)carbonyl] (pyridin-2-yl)amino\}imino)methyl]-2phenylpyrimidin-4-yl $\}$ methylidene)amine (A) $\left(\mathrm{C}_{40} \mathrm{H}_{50} \mathrm{~N}_{12} \mathrm{O}_{6}\right)$

The procedure, adapted from Brook et al. ${ }^{44}$, is as follows: $0.5 \mathrm{~g}(0.63 \mathrm{mmol})$ of 2-phenyl-pyrimidine-4,6-dicarbaldehyde bis(2-pyridyl hydrazone) was suspended in $50 \mathrm{~mL}$ toluene, and 5 equivalents, or $0.318 \mathrm{~g}$ or $0.438 \mathrm{~mL}(3.1 \mathrm{mmol})$ of triethylamine were added, and the mixture was stirred. Then, $2 / 3$ of an equivalent of triphosgene, i.e. $0.124 \mathrm{~g}(0.42 \mathrm{mmol})$ triphosgene, dissolved in toluene, was added dropwise, with stirring. After three hours of reaction time, approximately 5 


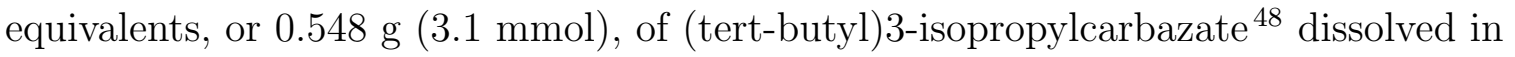
toluene were added to the reaction flask, dropwise, with stirring. The solution was stirred overnight. Then the contents of the reaction flask were gravity filtered, and the filtrate was evaporated to yield mostly the product, A (Figure 48), as well as excess isopropyl BOC hydrazide. The product was purified by column chromatography with $\mathrm{SiO}_{2}$ as the stationary phase and $\mathrm{CH}_{2} \mathrm{Cl}_{2}$ /ethyl acetate, 90:10 as eluent. ${ }^{1} \mathrm{H}$ NMR $\mathrm{CDCl}_{3} \delta$, ppm: 8.53 (bs, 2H), 8.28 (d, 2H), 8.12 (s, 2H), 7.76 $(\mathrm{d}, 2 \mathrm{H}), 7.60(\mathrm{~d}, 2 \mathrm{H}), 7.49(\mathrm{t}, 4 \mathrm{H}), 7.26(\mathrm{~m}, 1 \mathrm{H}), 7.23(\mathrm{~d}, 1 \mathrm{H}), 7.23(\mathrm{~s}, 1 \mathrm{H}), 7.16(\mathrm{~d}$, 1H), $7.05(\mathrm{~d}, 2 \mathrm{H}), 6.89(\mathrm{~d}, 1 \mathrm{H}), 6.72(\mathrm{~s}, 1 \mathrm{H}), 6.19(\mathrm{~s}, 4 \mathrm{H}), 1.45(\mathrm{~m}, 1 \mathrm{H}), 1.39(\mathrm{~s}$, 2H), $1.30(\mathrm{~d}, 9 \mathrm{H}), 1.29(\mathrm{~d}, 9 \mathrm{H}), 1.25(\mathrm{~s}, 1 \mathrm{H}) .{ }^{13} \mathrm{C} \mathrm{NMR} \mathrm{CDCl}_{3} \delta, \mathrm{ppm}: 166.78$, 163.36, 157.82, 157.35, 149.81, 140.52, 139.42, 132.52, 130.86, 130.34, 130.22, 130.05, 120.78, 52.49, 31.52, 30.33, 29.89, 22.44, 21.22. IR wavenumbers, $\mathrm{cm}^{-1}$ : 3300, broad (N-H stretch); 3000 (C-H stretch), 2940 (C-H), 1700, strong (C=O), 1600 (N-H bend), 1475 (- $\mathrm{CH}_{2}$ - bend), 1450 (- $\mathrm{CH}_{3}$ - bend). Electrospray-MS m/z (relative intensity) $795(\mathrm{M}+1,75) 595$ (67), 490 (100).

Synthesis of 6-\{6-[6-oxo-1-(propan-2-yl)-5-(pyridin-2-yl)-1,2,4,5tetrazinan-3-yl]-2-phenylpyrimidin-4-yl\}-2-(propan-2-yl)-4-(pyridin-2-yl)1,2,4,5-tetrazinan- 3-one (B) $\left(\mathrm{C}_{30} \mathrm{H}_{34} \mathrm{~N}_{12} \mathrm{O}_{2}\right)$

The procedure, adapted from Brook et al. ${ }^{44}$, is as follows: $0.1 \mathrm{~g}(0.13 \mathrm{mmol})$ of the product of the triphosgene reaction, molecule A, was mixed with an excess of 2 $\mathrm{M} \mathrm{HCl}$, (about $1 \mathrm{~mL}$ ) for about $1 \mathrm{~min}$. Aqueous sodium bicarbonate was added to neutralize the solution, and then the solution was extracted with dichloromethane and the organic layer evaporated to yield $\mathrm{B}$ (Figure 48). ${ }^{1} \mathrm{H} \mathrm{NMR} \mathrm{CDCl}_{3} \delta$, ppm: $8.35(2 \mathrm{H}, \mathrm{dd}, \mathrm{J}=4.95 \mathrm{~Hz}), 8.31(2 \mathrm{H}, \mathrm{dd}, \mathrm{J}=7.8), 8.25(\mathrm{dd}, \mathrm{J}=6.945), 7.86$ (q), 7.65 (d), 7.63 (dd, J = 15.6), 7.62 (d), 7.42 (q), 6.97 (dd, J = 7.2), 5.09 (t), 4.86 $(\mathrm{dd}, \mathrm{J}=22.05), 4.65$ (doublet of quintets, $\mathrm{J}=2.1), 1.16(\mathrm{dd}, \mathrm{J}=6.45), 1.09$ (d), 


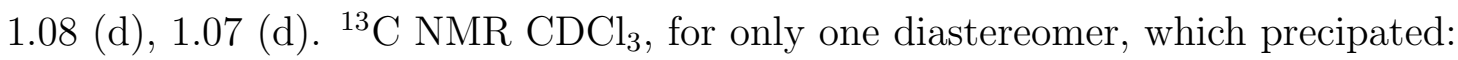
$\delta$, ppm: 164.95, 163.78, 153.63, 153.15, 147.79, 137.64, 136.02, 131.97, 128.90, 128.80, 119.98, 119.83, 118.09, 71.61, 47.96, 19.67, 19.07. IR (film on $\mathrm{NaCl}$ plate)wavenumbers, $\mathrm{cm}^{-1}: 3250$ (N-H stretch), 2990 (C-H stretch), 2970 (C-H stretch), $1700(\mathrm{C}=\mathrm{O}), 1680(\mathrm{C}=\mathrm{O}), 1600(\mathrm{~N}-\mathrm{H}$ bend $), 1580(\mathrm{~N}-\mathrm{H}$ bend $), 1560(\mathrm{~N}-\mathrm{H}$ bend), 1480 (- $\mathrm{CH}_{2}$ - bend), 1440 (- $\mathrm{CH}_{3}$ - bend). Electrospray-MS: m/z (relative intensity) $595(\mathrm{M}+1,100), 360$ (98), 280 (20).

Synthesis of 2-Isopropyl-6-\{6-[5-isopropyl-6-oxo-1-(2-pyridyl)-4,5dihydro-1H-1,2,4,5-tetrazin-3-yl]-2-phenyl-4-pyrimidinyl\}-4-(2-pyridyl)2,4-dihydro-1H-1,2,4,5-tetrazin-3-one (Ditopic Verdazyl Ligand) $\left(\mathrm{C}_{30} \mathrm{H}_{28} \mathrm{~N}_{12} \mathrm{O}_{2}\right)$

The following procedure was used; it was adapted from Brook et al. ${ }^{44}$ : first, in 40:60 methanol:water solution, $0.05 \mathrm{~g}$ B was stirred with 3 equivalents of sodium periodate, $\mathrm{NaIO}_{4}$, for $30 \mathrm{~min}$. The mixture was extracted with dichloromethane and the organic layer evaporated, yielding the yellowish ligand (Figure 47; Figure 48). Attempts to purify the ligand by column chromatography using $\mathrm{SiO}_{2}$ as the stationary phase were unsuccessful; the ligand may have decomposed on the column. IR (film on NaCl plate) wavenumbers, $\mathrm{cm}^{-1}: 3400$ (N-H stretch), 3200 ( $\mathrm{N}-\mathrm{H}$ stretch), 3050, 2980 strong (C-H stretch), 2920 strong (C-H stretch), 1700 strong $(\mathrm{C}=\mathrm{O}), 1580\left(\mathrm{~N}-\mathrm{H}\right.$ bend), $1560(\mathrm{~N}-\mathrm{H}$ bend $), 1460\left(-\mathrm{CH}_{2^{-}}\right.$bend $), 1440\left(-\mathrm{CH}_{3^{-}}\right.$ bend). The N-H peaks appear to be from partly oxidized impurities. ESR data, measured in toluene: $\mathrm{g}=2.002,|D /(h c)|=0.0040 \mathrm{~cm}^{-1}$.

\section{Coordination to nickel}

The following procedure, adapted from Brook et al. ${ }^{44}$, was used: to acetonitrile was added $0.025 \mathrm{~g}\left(4.2472 \times 10^{-5} \mathrm{~mol}\right)$ of the ditopic verdazyl ligand, and the mixture was stirred until dissolution occurred. Then, one equivalent, $0.015 \mathrm{~g}$, of 
nickel triflate dissolved in acetonitrile was added, with stirring. The color of the solution changed to brown. The reaction was completed within 5 min. Then, sodium hexafluorophosphate was added to the solution and the mixture stirred. The coordination compound may have been isolated as a solid on filter paper from vacuum filtration using a Hirsch funnel. ${ }^{44}$

\section{Titration Experiment}

A slow titration of a solution of nickel(II) triflate in acetonitrile into a solution of the ditopic verdazyl ligand in acetonitrile was performed, while measuring the UV-Vis spectrum of the solution at regularly spaced time intervals. As shown in Figure 58, there was a well-defined endpoint to the titration curve of the molar absorptivity at $568 \mathrm{~nm}$ vs. ratio of concentration of nickel to concentration of ligand. The ratio at the endpoint was approximately 1:1. ESI-mass spectrometry recorded on this solution gave a peak at $\mathrm{m} / \mathrm{z} 2595$, which is approximately the mass to charge ratio of the anticipated grid complex with a +1 charge. 


\section{SYNTHESIS}
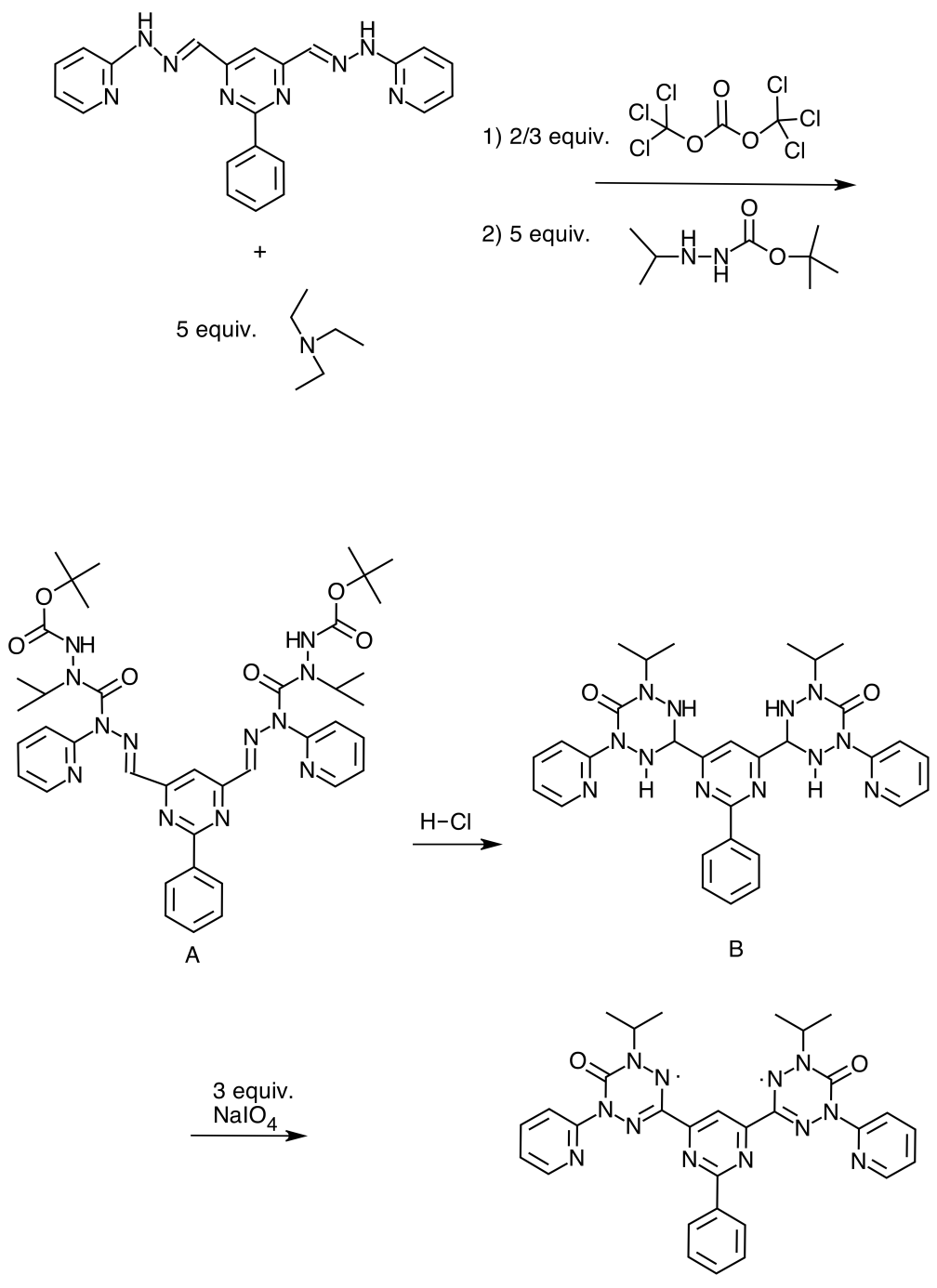

Figure 48. Synthesis, including triphosgene reaction, deprotection, and oxidation.

The triphosgene reaction, shown in Figure 48, was probably the most involved reaction; certainly it was the most involved reaction of the new chemical reactions performed in this project. It was originally developed by Brook et al. ${ }^{42}$, and it was adapted for the bis-hydrazone starting material used in this project. Phosgene gas is highly toxic and so for this synthesis it was better to avoid using phosgene gas 
directly. Triphosgene is a solid whose formula is equivalent to three molecules of phosgene gas, and so two-thirds of an equivalent of triphosgene was used in place of two equivalents of phosgene gas. After dropwise addition of the triphosgene, dissolved in toluene, to the solution of bis-hydrazone suspended in toluene with an excess of triethylamine, the reaction mixture was stirred for three hours. Then an excess of (tert-butyl)3-isopropylcarbazate dissolved in toluene was added and the mixture stirred overnight. The reaction mixture was filtered to remove the triethylamine hydrochloride, and the filtrate was evaporated to yield the product, A.

This synthetic step worked reasonably well once the correct stoichiometry was used for the first part of this synthetic step. For the first several trials of this reaction, an incorrect stoichiometry was implemented in which two equivalents of triphosgene were used. But since one molecule of triphosgene is equivalent to three molecules of phosgene, only two-thirds of an equivalent of triphosgene should have been used. This is true since only two equivalents of phosgene were required, one for each hydrazone group, and too much excess could cause problems with the reaction. The reaction was initially performed under nitrogen in order to prevent moisture from contaminating the reaction mixture and reacting with the triphosgene, but on further investigation, this was found to be unnecessary. Eventually, on one of the trials of this reaction, the product crystallized. Four equivalents of triethylamine were needed for the reaction, but a slight excess, five equivalents, of triethylamine were used. Similarly, two equivalents of (tert-butyl)3-isopropylcarbazate were needed, but an excess, five equivalents, of (tert-butyl)3-isopropylcarbazate were used. Using a large excess of (tert-butyl)3-isopropylcarbazate made the reaction cleaner and increased the yield. 
The deprotection of the triphosgene reaction product $A$ was done by mixing $A$ with an excess of hydrochloric acid; the product was then extracted with dichloromethane and the organic layer evaporated. This reaction ran cleanly and left behind most impurities. The product bis-tetrazane, $B$, has two chiral centers, so three stereoisomers of the product bis-tetrazane $B$ can form: $R, R ; S, S$; and $R, S$. The $R, R$ has the same NMR spectrum as the $S, S$ isomer since they are enantiomers, but the two diastereomers: $R, R$ and $R, S$, have different NMR spectra. All stereoisomers of the bis-tetrazane $B$ are oxidized to the same ditopic bis-verdazyl ligand, so there is no need to separate the diastereomers.

The oxidation of the bis-tetrazane to the ligand was performed in a mixture of water and methanol because sodium periodate is not very soluble in methanol, so water is needed to dissolve it completely. It worked moderately well, and the major impurity in the product ditopic bis-verdazyl ligand other than starting material was the monoradical formed when only one tetrazane unit oxidized to form a verdazyl.

\section{CHARACTERIZATION AND PROPERTIES}

A bis-verdazyl ligand was clearly synthesized. It is clear that ESR in frozen toluene indicated the presence of a diradical.

A monoradical has two possible spin states for its unpaired electron, denoted by the two values of the spin-angular-momentum quantum number $m_{s}: m_{s}=-1 / 2$ and $m_{s}=+1 / 2$. For a monoradical, ESR records the transition of the unpaired electron from $m_{s}=-1 / 2$ to $m_{s}=+1 / 2$. An energy diagram showing this transition is shown in Figure 49. A diradical has three possible spin states for its unpaired electrons, denoted by the three values of the spin-angular-momentum quantum number $m_{s}: m_{s}=-1, m_{s}=0$, and $m_{s}=+1$. The ESR records the transition from 
$m_{s}=-1$ to $m_{s}=0$, the transition from $m_{s}=0$ to $m_{s}=+1$, and the transition from $m_{s}=-1$ to $m_{s}=+1$. These three transitions for the diradical involve equal changes in energy, as shown in Figure 50, and the transitions from $m_{s}=-1$ to $m_{s}=0$ and from $m_{s}=0$ to $m_{s}=+1$ both occur at the same magnetic field strength, while the transition from $m_{s}=-1$ to $m_{s}=+1$ occurs at half the magnetic field strength at which the transitions from $m_{s}=-1$ to $m_{s}=0$ and from $m_{s}=0$ to $m_{s}=+1$ occur. Diradicals also exhibit zero field splitting; when the applied magnetic field strength is zero, the energies of the three spin states are each different due to a magnetic field that is exerted by the unpaired electrons on each other (Figure 51). As a result, the transitions from $m_{s}=-1$ to $m_{s}=0$ and from $m_{s}=0$ to $m_{s}=+1$ are not at exactly the same magnetic field; there is splitting.

The main part of the first derivative spectrum of the ESR of the ligand in frozen toluene, shown in Figure 52, contains one peak in the middle and two peaks on either side. These two pairs of peaks on either side are the peaks from the two transitions, $m_{s}=-1$ to $m_{s}=0$ and $m_{s}=0$ to $m_{s}=+1$. The middle peak is from monoradical impurities, from the transition from $m_{s}=-1 / 2$ to $m_{s}=+1 / 2$. The distance between the outer peaks in the main field spectrum was measured, and half this distance, $D^{\prime}$, was about 85 Gauss (Figure 53). ${ }^{51}$ Based on $D^{\prime}$, the zero-field splitting (ZFS) parameter $D$ was calculated; $D$ is directly proportional to $D^{\prime} . D$ is reported as $|D /(h c)|$; for the ligand, $|D /(h c)|$ was calculated to be $0.0040 \mathrm{~cm}^{-1}$. For comparison, Hicks' para - benzene bridged verdazyl had a | $D /(h c) \mid$ value equal to $0.00210 \mathrm{~cm}^{-1}$, while the meta - benzene bridged verdazyl had a ZFS parameter $|D /(h c)|$ equal to $0.00348 \mathrm{~cm}^{-138}$. The $|D /(h c)|$ values for the Hicks' meta-bis-verdazyl molecule and the bis-verdazyl ligand, which is also meta, are reasonably close. For further comparison, Brook's methylene-bridged verdazyl had a $|D /(h c)|$ value of $0.023 \mathrm{~cm}^{-1} .50$ This is not as close to the value 
$0.0040 \mathrm{~cm}^{-1}$ observed for the ligand, but there is only a methylene group between the two verdazyls in Brook's methylene-bridged verdazyl, rather than an aromatic ring. The value of $D$ increases as the distance between two unpaired electrons of the diradical decrease; if $r$ is the distance between the two unpaired electrons of the diradical, $D \propto 1 / r^{3}{ }^{38}$

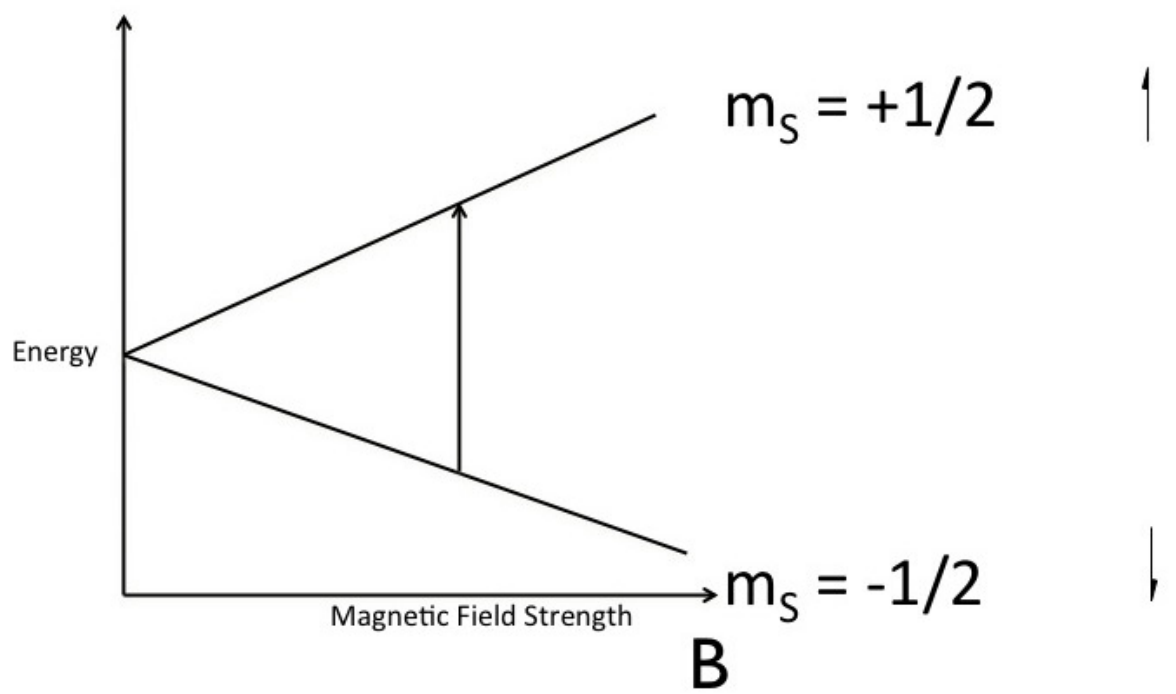

Figure 49. Energy diagram for a monoradical. 


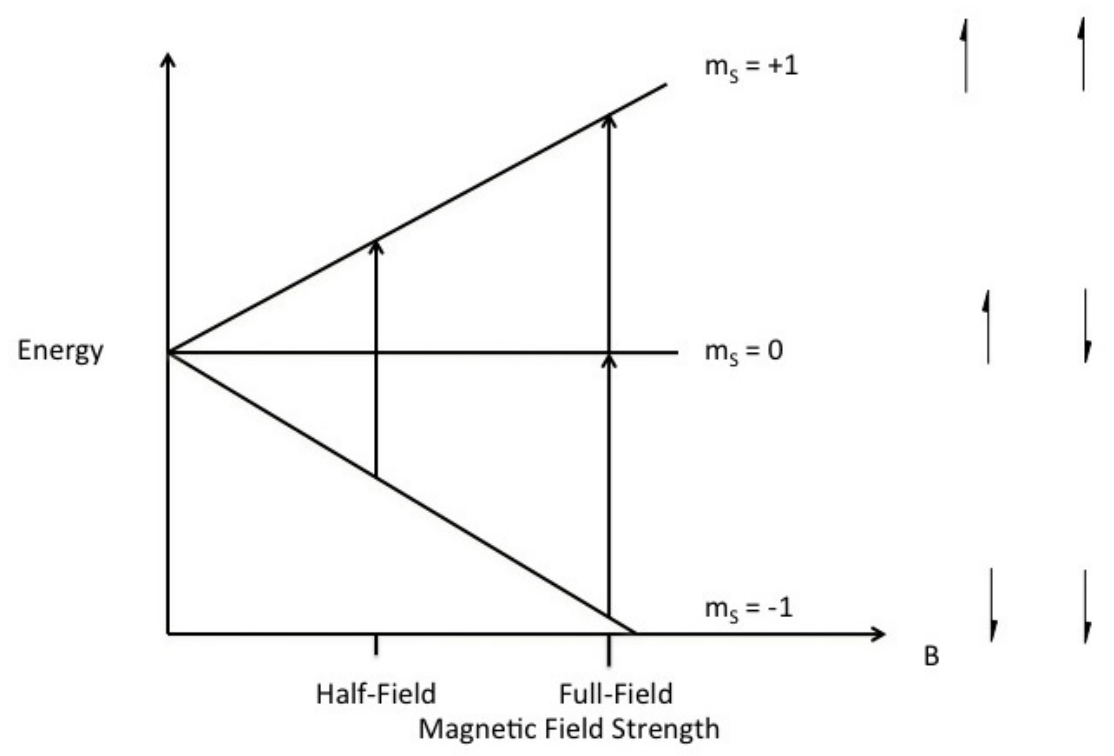

Figure 50. Energy diagram for a diradical.

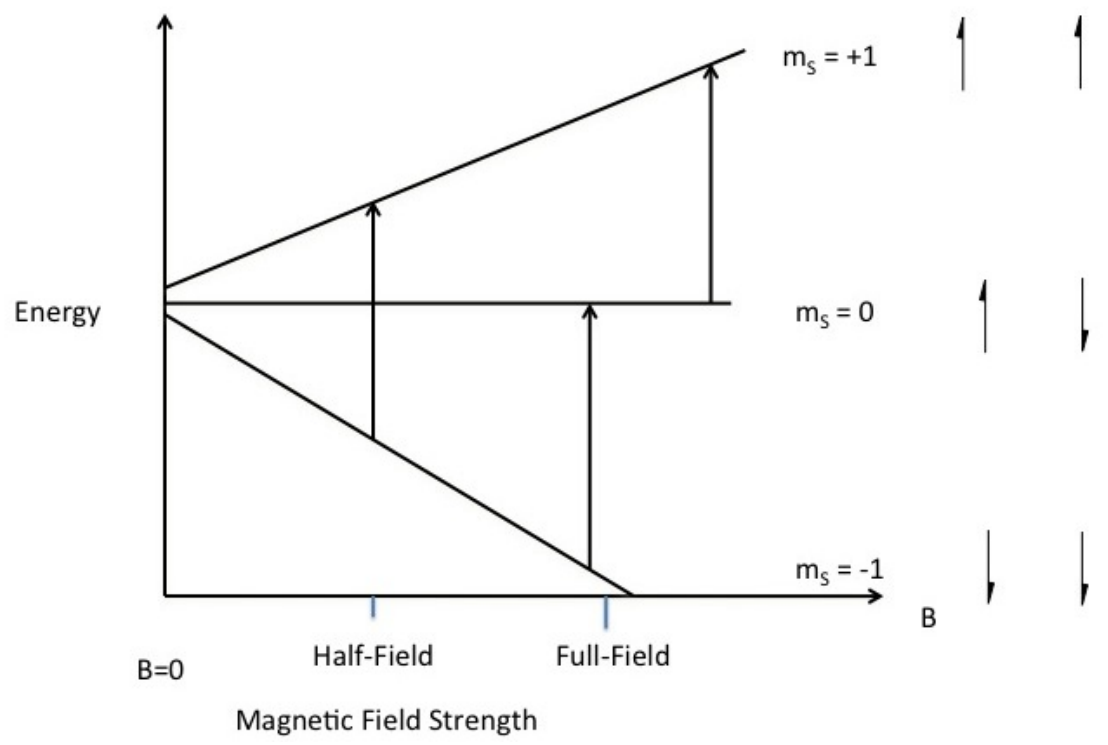

Figure 51. Energy diagram for a diradical, showing zero-field splitting. 


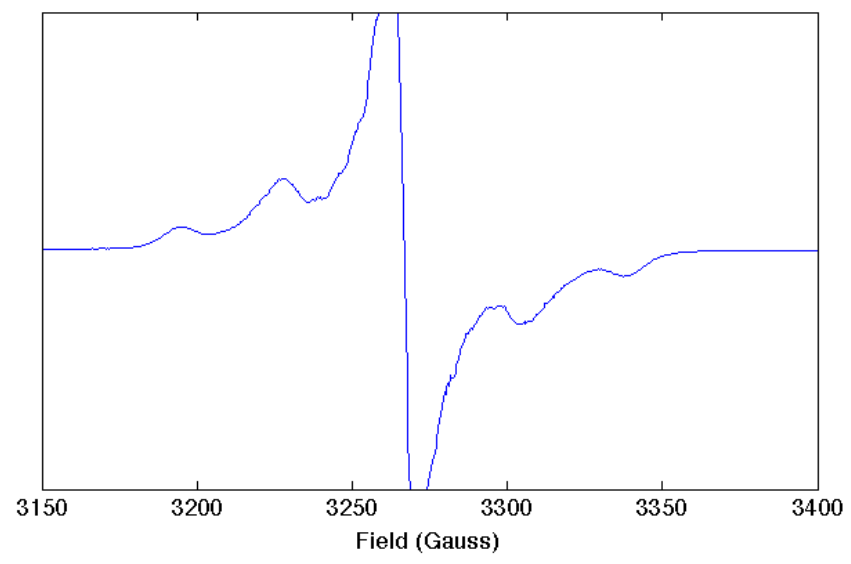

Figure 52. First derivative of ESR absorption spectrum of ditopic verdazyl ligand in frozen toluene, main part of the spectrum.

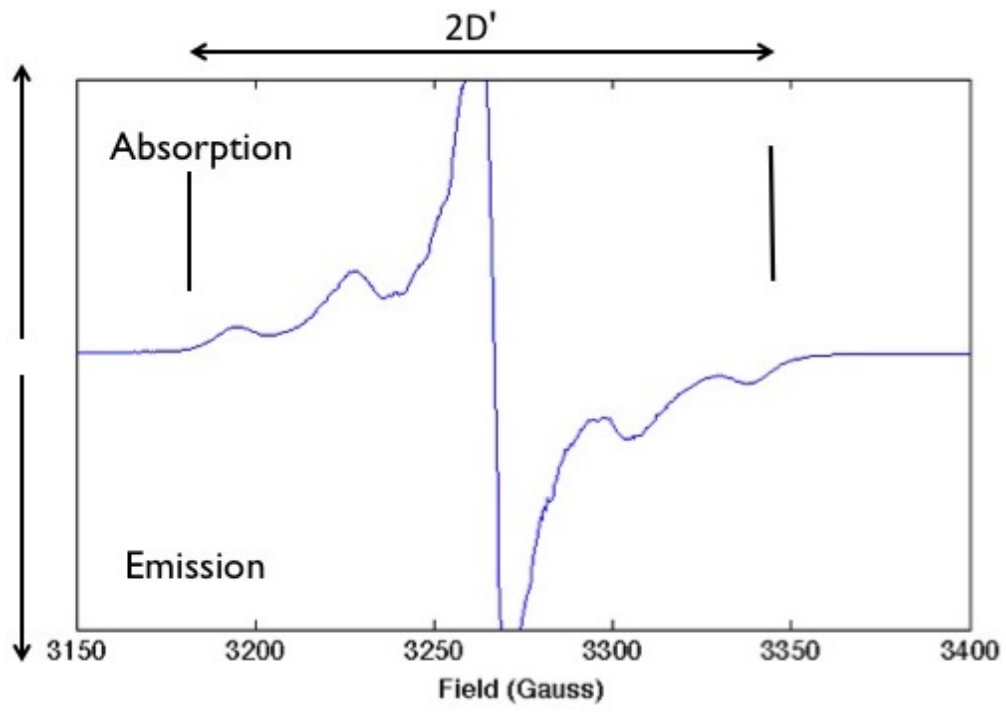

Figure 53. Illustration of how to calculate the $D^{\prime}$ parameter from the ESR spectrum in frozen toluene.

In addition, the ESR in frozen toluene showed a half-field signal, shown in Figure 54, a clear indication that a diradical is present in the sample. 


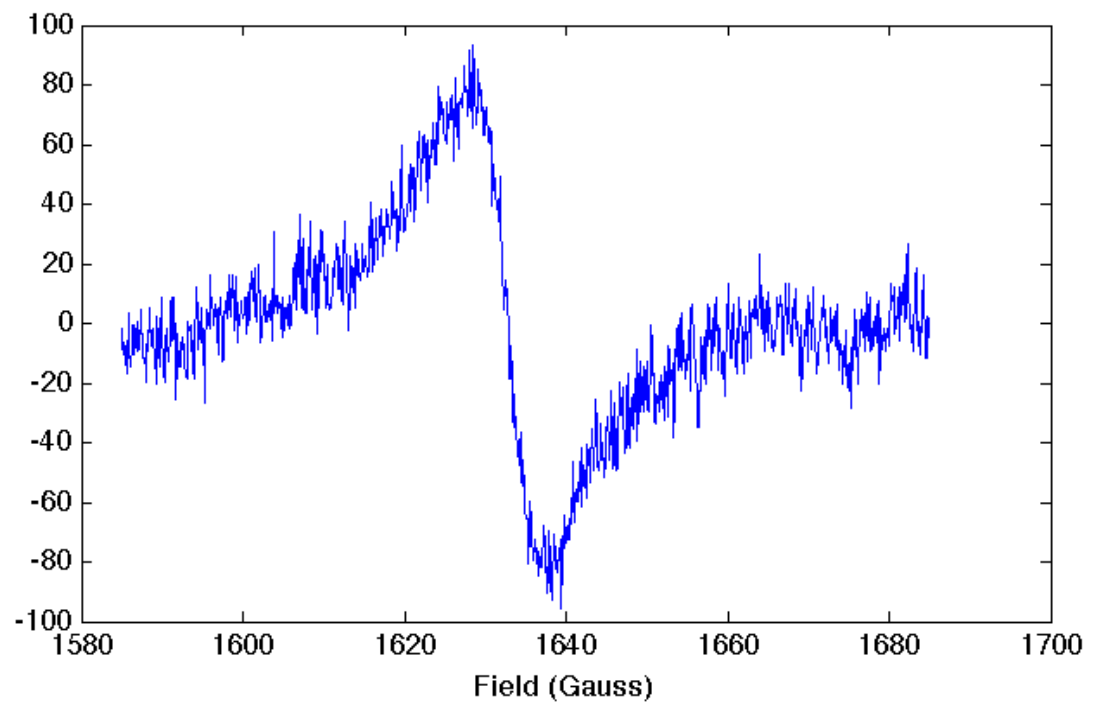

Figure 54. First derivative of ESR absorption spectrum of ditopic verdazyl ligand in frozen toluene, half-field spectrum.

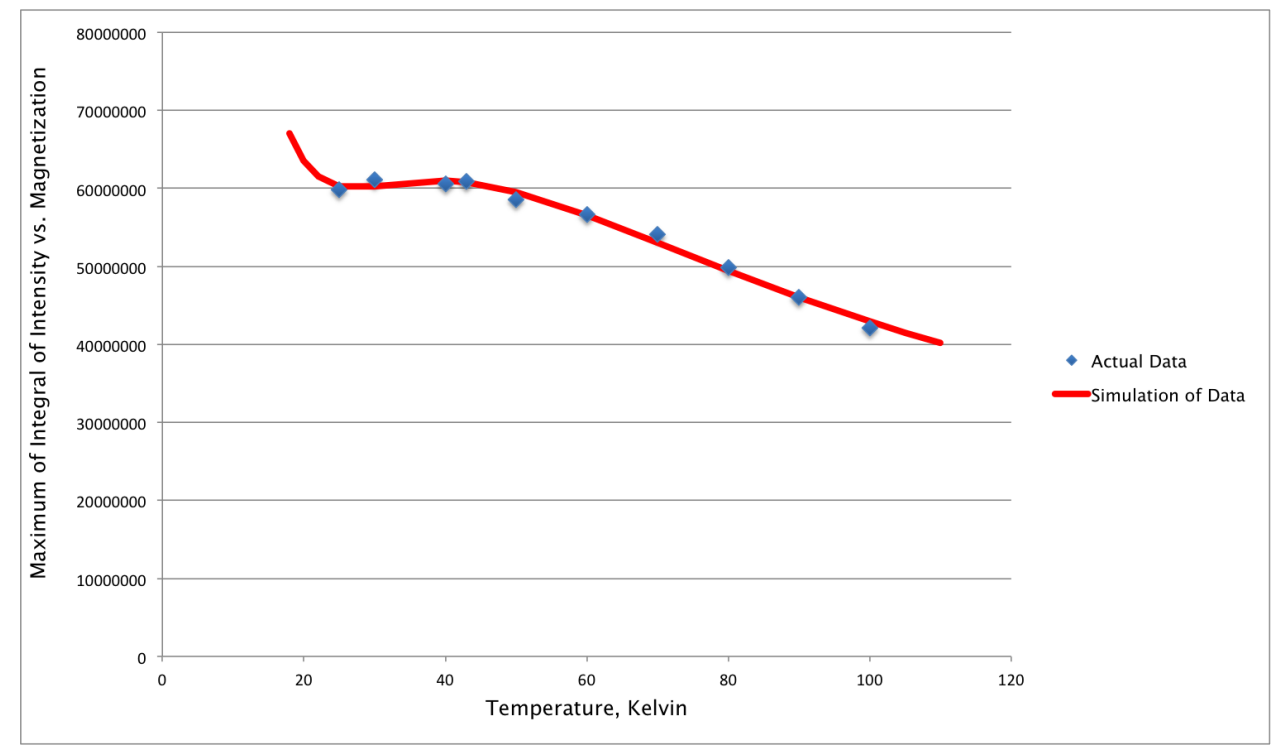

Figure 55. Variable-temperature ESR results and curve-fitting.

When variable-temperature ESR was performed at temperatures ranging from $100 \mathrm{~K}$ to $25 \mathrm{~K}$, the maximum of the integral of intensity vs. magnetization changed 
with decrease in temperature, increasing at first as temperature dropped from 100 $\mathrm{K}$, then leveling off at about $40 \mathrm{~K}$, as shown in Figure 55. The singlet state of the molecule does not have an ESR spectrum, while the triplet state does have an ESR spectrum. Thus the observation that as the temperature continued to decrease below $40 \mathrm{~K}$, the intensity of the spectrum leveled off and started to decrease indicates clearly that this bis-verdazyl has a singlet ground state (Figure 55).

The fitting of the curve for integral of intensity of ESR signal vs. temperature, shown in Figure 55, was performed using a modified Bleany-Bowers equation with an additional term to account for the monoradical impurity; the equation is $I=q / T+(p / T) * 1 /\left(3+\mathrm{e}^{(J / T)}\right)$, where $\mathrm{p}$ and $\mathrm{q}$ are proportionality constants and $J$ is the singlet-triplet separation in $\mathrm{cm}^{-1} .{ }^{49}$ From this curve fitting, $J$ was calculated to be $-93 \mathrm{~cm}^{-1}$. For comparison, Hicks' para-benzene-bridged verdazyl had a singlet-triplet separation, $J$, equal to $-29.73 \pm 0.03 \mathrm{~cm}^{-1} .{ }^{38}$ For further comparison, Brook's methylene-bridged verdazyl had a singlet-triplet separation, $J$, equal to $-150 \pm 10 \mathrm{~cm}^{-1} .50$ The Hicks para-benzene-bridged verdazyl had a negative singlet-triplet separation, which means that the ground state for Hicks' diradical is a singlet state. The Hicks meta-benzene-bridged verdazyl had a singlet-triplet separation, $J$, equal to $19.3 \pm 1.7 \mathrm{~cm}^{-1}$. The $J$ value for the meta-benzene-bridged verdazyl is positive, indicating that the ground state for this molecule is a triplet ground state. One of the differences between Hicks' meta-benzene-bridged verdazyl and the bis-verdazyl ligand are that the aromatic ring between the two radicals in Hicks' molecule is a benzene while the aromatic ring between the two radicals in the bis-verdazyl ligand is a pyrimidine ring.

Based on this observation, Hückel MO calculations were performed on simpler systems that resemble these two molecules: 1,3 dimethylene benzene diradical, which resembles Hicks' molecule because a benzene bridges the two radicals and 
4,6-dimethylene pyrimidine diradical, which resembles the ligand because a pyrimidine ring bridges the two radicals. Meta-dimethylene benzene diradical showed a triplet ground state as can be seen by the Hückel MO matrix having only seven distinct eigenvalues, with the eigenvalue 0 having a multiplicity of 2 , while 4,6-dimethylene pyrimidine diradical showed a singlet ground state as can be seen by the Hückel MO matrix having eight distinct eigenvalues. The spin multiplicities of the ground states of these two simpler systems, based on Hückel MO calculations, are consistent with the observed ground-state multiplicities of the Hicks bis-verdazyl molecule and of the bis-verdazyl ligand.

Semi-empirical AM1 calculations were also performed on these two simpler systems, and they also indicated that the ground state of 1,3-dimethylene benzene diradical is a triplet state and that the ground state of 4,6-dimethylene pyrimidine diradical is a singlet ground state. Qualitative MO diagrams depicting the $\pi$ orbitals for these systems are depicted in Figure 56, along with pictures of the two highest energy orbitals in each MO diagram. The pictures were generated with the program Spartan 2014 based on the semi-empirical AM1 calculations, which were also performed using Spartan 2014. 


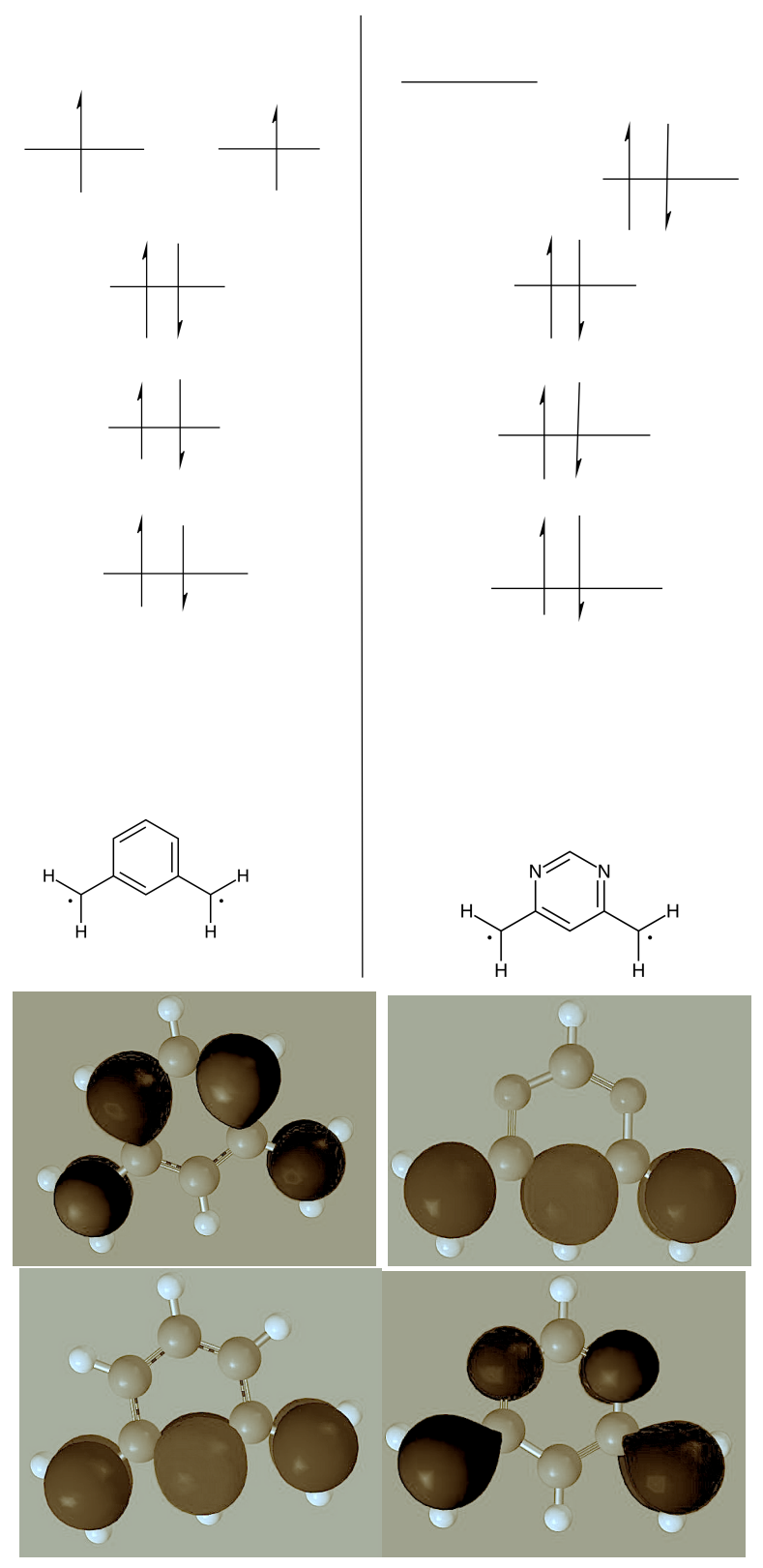

Figure 56. MO diagrams representing 10-atom molecules and pictures of HOMOs based on semi-empirical AM1 calculations. Pictures of HOMOs on the left, as well as the MO diagram on the left, are for 1,3-dimethylene benzene diradical, and pictures of HOMOs on the right, as well as the MO diagram on the right, are for 4,6 dimethylene pyrimidine diradical.

In the 1,3-dimethylene benzene diradical, the two highest occupied molecular orbitals each contain one of the two unpaired electrons. Since the two unpaired 
electrons occupy separate orbitals at the same energy, the spin quantum number for the unpaired electrons of 1,3-dimethylene benzene is 1 , and the spin multiplicity is $2 S+1=2(1)+1=3$, so the ground state is a triplet state. Since the pyrimidine ring has nitrogens at the 1 and 3 positions, and nitrogens have lower energy $\mathrm{p}$ orbitals compared to the carbons in positions 4 and 6 of 1,3-dimethylene benzene diradical, when the $\mathrm{p}$ orbitals of the nitrogens combine with the $\mathrm{p}$ orbitals of the carbons to form a molecular orbital, the resulting molecular orbital is also lower in energy. So compared to the MO diagram for 1,3-dimethylene benzene diradical, the MO diagram for 4,6-dimethylene pyrimidine diradical has one of the two highest energy molecular orbitals moved down in energy so it is lower than the other one, and so in the ground state, the unpaired electron from the higher of the two orbitals moves down to the lower of the two orbitals, joining the other unpaired electron, so that both unpaired electrons occupy the same molecular orbital. As a result, in the ground state the spins are antiparallel, the spin quantum number is 0 , and the spin multiplicity of the ground state is $2 S+1=2(0)+1=1$, so the ground state of 4,6-dimethylene pyrimidine diradical is a singlet state.

In addition, the ESR spectrum of the ligand in liquid acetonitrile was recorded; the spectrum is shown in Figure 57. It shows nine peaks for the $2 N+1$ splitting of a verdazyl; since the unpaired electron is shared among four nitrogens, $N=4$ and so there are $2 N+1=9$ peaks. There are also smaller peaks superimposed on these peaks for coupling with the isopropyl groups and with the pyridine nitrogens; this coupling is weaker than with the verdazyl nitrogens, so the splitting is less prominent. 


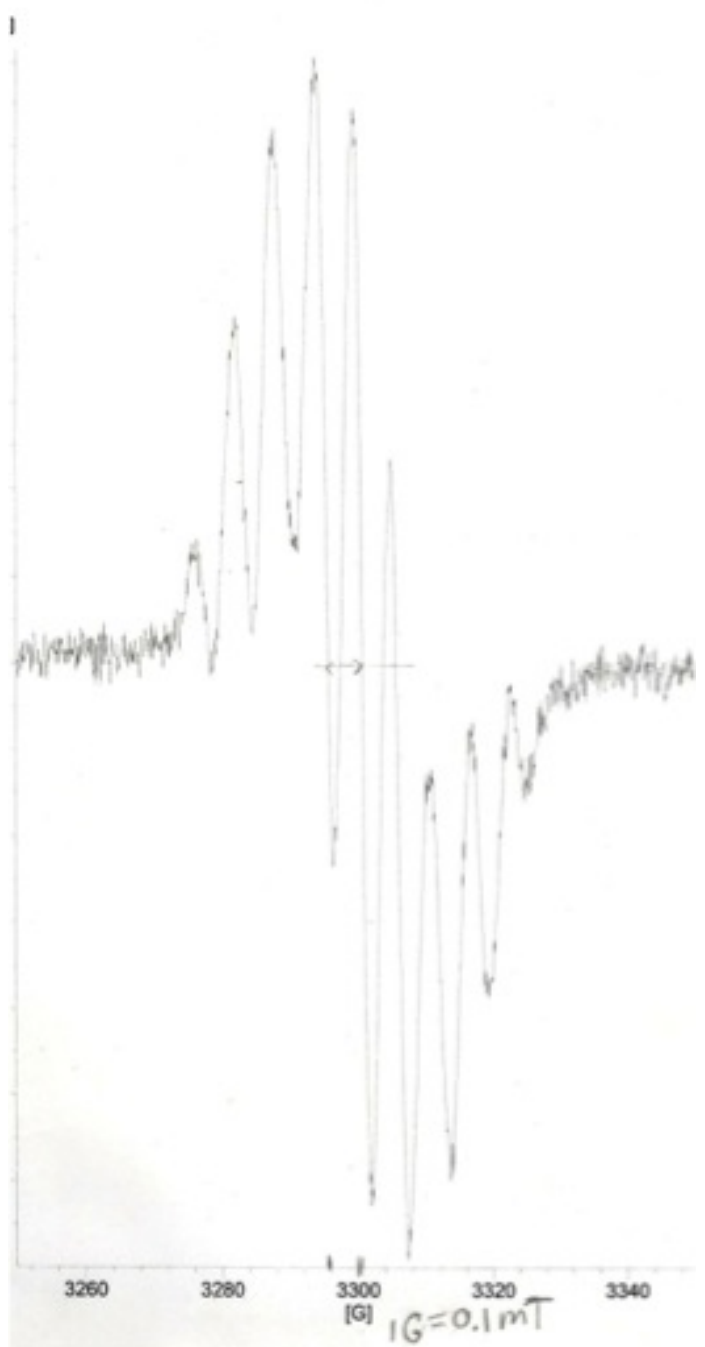

Figure 57. ESR in acetonitrile.

Mixture of the ligand with nickel(II) triflate resulted in binding, as demonstrated by the presence of a well-defined endpoint to the titration of the ligand with nickel. Self-assembly occurred to form the grid complex, as evidenced by the ESI-mass spectrometry and UV-Vis spectrometry.

While the solution of the ligand in acetonitrile turned brown once the nickel(II) triflate in acetonitrile was mixed with it, it seemed to change color from brown to purple on standing in air; however, the significance of the various colors of the 
solution is unknown. It is abundantly clear that the purple solution did not show the molecular ion of the grid complex in the mass spectrometry experiment on at least one occasion and so it is most likely that the correct color of the complex is brown.

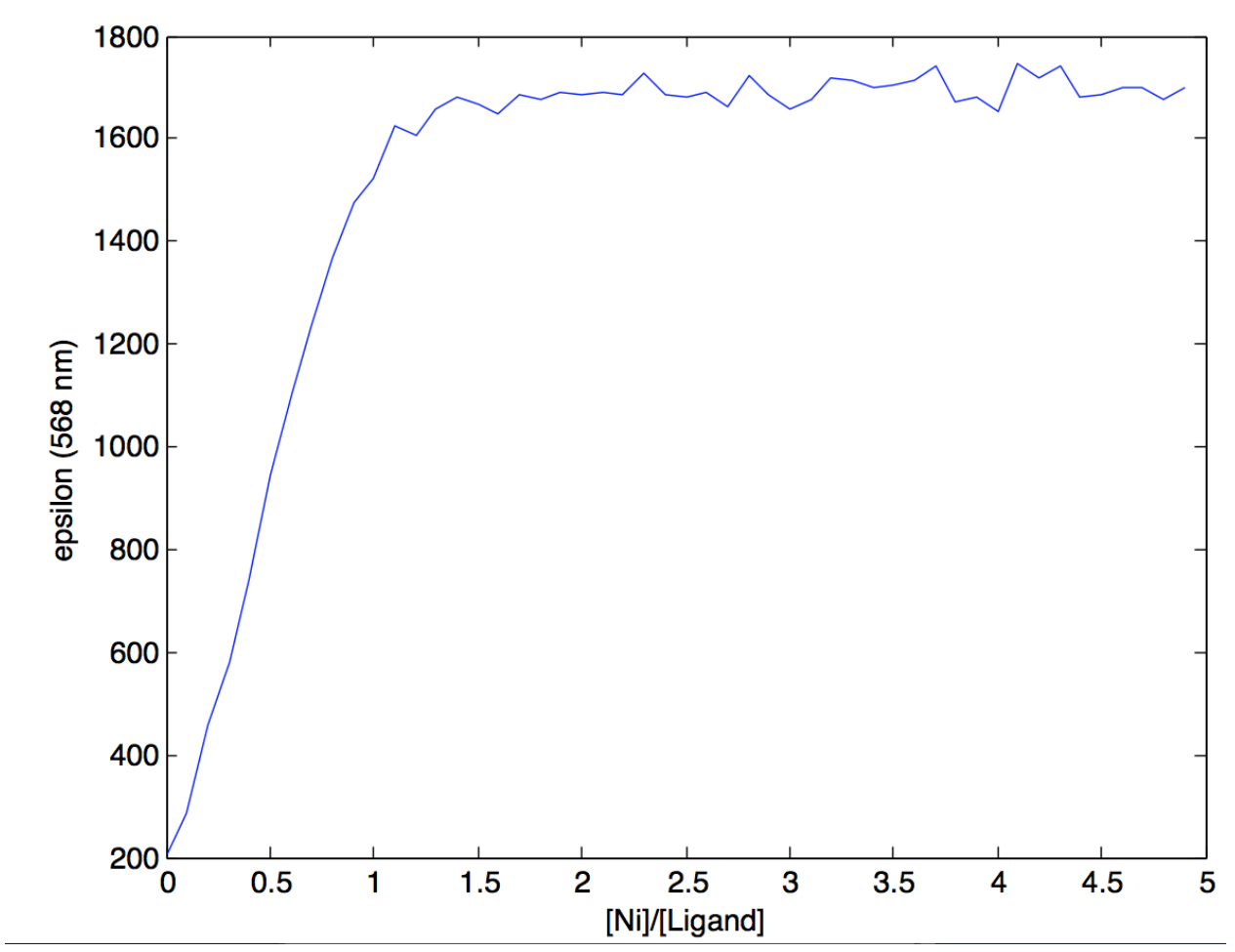

Figure 58. Titration data.

Figure 58 shows titration data obtained by recording UV-vis spectra as a solution of nickel triflate was added to solution of the verdazyl ligand. There is a well-defined endpoint to the titration curve, indicating that binding occurred and the ratio of ligand to nickel at the endpoint is approximately 1:1. This indicates that likely either a grid complex formed or a polymer formed; partially formed grids would have either a $2: 1$ or a $3: 2$ ratio of ligand to nickel. However as no precipitate formed, it is less likely that a polymer formed, so the results of this titration experiment suggest that the form of the coordination compound of the ligand with 
nickel is most likely a square grid. Also, ESI-MS was performed on the product and a peak appeared at $\mathrm{m} / \mathrm{z} 2595$, which is a possible mass-to-charge ratio of the planned grid complex with a +1 charge.

\section{CONCLUSION}

This work characterized a new, previously unsynthesized verdazyl ligand and was moderately successful in demonstrating self-assembly. Also successful was the crystallization of the product of the triphosgene reaction, and there is a definite prospect of future elemental analysis on said product. It is hoped that this research project's state of being incomplete, in that a crystal structure of the grid was not obtained, will inspire scientists to re-investigate this problem. What makes self-assembled grids with magnetic ligands so fascinating is their potential for use in information storage due to the ability of technology to control spin states of the complex. Another aspect of these grids that makes these grids fascinating is that magnetic interactions in coordination complexes of free radicals and transition metals include ferromagnetism and antiferromagnetism and various mixtures of these two types of interactions. 


\section{BIBLIOGRAPHY}

1. Patroniak, V.; Baxter, P.N.W.; Lehn, J.-M.;Kubicki, M.; Nissinen, M. and Rissanen, K. Eur. J. Inorg. Chem. 2003, 4001-4009.

2. Chi, X.; Guerin, A.J.; Haycock, R.A.; Hunter, C.A.; Sarson, L.D. J. Chem. Soc., Chem. Commun. 1995, 2567-2569.

3. AlQaisi, S.M.; Galt, K.J.; Chai, M.; Ray III, D.G.; Rinaldi, P.L,; Tessier, C.A.; Youngs, W.J. J. Am. Chem. Soc. 1998, 120, 12149-12150.

4. Hasenknopf, B.; Lehn, J.-M.; Boumediene, N.; Dupont-Gervais, A.; Van Dorsselaer, A.; Kneisel, B.; Fenske, D. J. Am. Chem. Soc. 1997, 119, 10956-10962.

5. Baxter, P.N.W.; Lehn, J.-M.; Kneisel, B. O.; Baum, G.; Fenske, D. Chem. Eur. J. 1999, 5, 113-120.

6. Cárdenas, D.J.; Gaviña, P.; Sauvage, J.-P. Chem. Commun. 1996,1915-1916.

7. Ulrich, S.; Lehn, J.-M. J. Am. Chem. Soc. 2009, 131, 5546-5559.

8. Ulrich, S.; Petitjean, A.; Lehn, J.-M. Eur. J. Inorg. Chem. 2010, 1913-1928.

9. Rojo, J.; Romero-Salguero, F.J.; Lehn, J.-M.; Baum, G.; Fenske, D. Eur. J. Inorg. Chem. 1999, 1421-1428.

10. Baxter, P.N.W.; Lehn, J.-M.; Kneisel, B.O.; Fenske, D. Chem. Commun. 1997, 2231-2232. 
11. Brooker, S.; Hay, S.J.; Plieger, P.G. Angew. Chem. Int. Ed. 2000, 39, 1968-1970.

12. Baxter, P.N.W.; Lehn, J.-M.; Fischer, J.; Youinou, M.-T. Angew. Chem. Int. Ed. Engl. 1994, 33, 2284-2287.

13. Zhao, L.; Matthews, C.J.; Thompson, L.K.; Heath, S.L. Chem. Commun. 2000, 265-266.

14. Groeneman, R.H.; MacGillivray, L.R.; Atwood, J.L. Chem. Commun. 1998, $2735-2736$.

15. Ruben, M.; Breuning, E.; Barboiu, M.; Gisselbrecht, J.-P.; Lehn, J.-M. Chem. Eur. J. 2003, 9, 291-299.

16. Ruben, M.; Breuning, E.; Gisselbrect, J.-P.; Lehn, J.-M. Angew. Chem. Int. Ed. 2000, 39, 4139-4142.

17. Crystal. Encyclopaedia Britannica [Online]; Encyclopædia Britannica Inc., 2014. Web. http://www.britannica.com/EBchecked/topic/145105/crystal (accessed Oct 18, 2014).

18. Hanan, G.S.; Arana, C.R.; Lehn, J.-M.; Fenske, D. Angew. Chem. Int. Ed. Engl. 1995, 34, 1122-1124.

19. Chaudhuri, P.; Verani, C.N.; Bill, E.; Bothe, E.; Weyhermüller, T.; Wieghardt, K. J. Am. Chem. Soc. 2001, 123, 2213-2223.

20. Verani, C.N.; Gallert, S.; Bill, E.; Weyhermüller, T.; Wieghardt, K.; Chaudhuri, P. Chem. Commun. 1999, 1747-1748. 
21. Sieger, M.; Kaim, W.; Stufkens, D. J.; Snoeck,T. L.; Stoll, H.; Záliš, S. Dalton Trans. 2004, 3815-3821.

22. Kaim, W. Inorg. Chem. 2011, 9752-9765.

23. Muresan, N.; Lu, C.C.; Ghosh, M.; Peters, J.C.; Abe, M.; Henling, L.M.; Weyhermöller, T.; Bill, E.; Wieghardt, K. Inorg. Chem. 2008, 47, 4579-4590.

24. Kapre, R.R.; Bothe, E.; Weyhermüller, T.; George, S.D.; Wieghardt, K. Inorg. Chem. 2007, 46, 5642-5650.

25. Rotthaus, O.; Jarjayes, O.; Thomas, F.; Philouze, C.; Del Valle, C.P.; Saint-Aman, E.; Pierre, J.-L. Chem. Eur. J. 2006, 2293-2302.

26. Herebian, D.; Both, E.; Neese, F.; Weyhermüller, T.; Wieghardt, K. J. Am. Chem. Soc. 2003, 125, 9116-9128.

27. Caneschi, A.; Gatteschi, D.; Renard, J. P.; Rey, P.; Sessoli, R. Inorg. Chem. 1989, 28, 1976-1980.

28. Benelli, C.; Caneschi, A.; Gatteschi, D.; Pardi, L.; Rey, P. Inorg. Chem. 1990, 29, 4223-4228.

29. Caneschi, A.; Gatteschi, D.; Renard, J. P.; Rey, P.; Sessoli, R. J. Am. Chem. Soc. 1989, 111, 785-786.

30. Luneau, D.; Risoan, G.; Rey, P.; Grand, A.; Caneschi, A.; Gatteschi, D.; Laugier, J. Inorg. Chem. 1993, 32, 5616-5622. 
31. Wang, H.; Liu, Z.; Liu, C.; Zhang, D.; Lu, Z.; Geng, H.; Shuai, Z.; Zhu, D. Inorg. Chem. 2004, 43, 4091-4098.

32. Shuvaev, K. V.; Sproules, S.; Rautiainen, J.M.; McInnes, E.J.L.; Collison, D.; Anson, C.E.; Powell, A.K. Dalton Trans. 2013, 42, 2371-2381.

33. Kuhn, R.; Trischmann, H. Angew. Chem. Internat. Edit. 1963, 2, 155.

34. Neugebauer, F. A.; Fischer, H. Angew. Chem. 1980, 92, 766.

35. Barclay, T.M.; Hicks, R.G.; Lemaire, M.T.; Thompson, L.K. Chem. Commun. 2000, 2141-2142.

36. Barclay, T.M.; Hicks, R.G.; Lemaire, M.T.; Thompson, L.K. Inorg. Chem. 2003, 42, 2261-2267.

37. Lemaire, M.T.; Barclay, T.M.; Thompson, L.K.; Hicks, R.G. Inorg. Chim. Act. 2006, 359, 2616-2621.

38. Gilroy, J.B.; McKinnon, S.D.J.; Kennephol, Pierre; Zsombor, M.S.; Ferguson, M.J.; Thompson, L.K.; Hicks, R.G. J. Org. Chem. 2007, 72, 8062-8069.

39. Brook, D.J.R.; Lynch, V.; Conklin, B. Fox, M.A. J. Am. Chem. Soc. 1997, 19, $5155-5162$.

40. Brook, D.J.R.; Fornell, S.; Noll, B.; Yee, G.T.; Koch, T.H. J. Chem. Soc., Dalton Trans., 2000, 2019-2022. 
41. Barclay, T.M.; Hicks, R.G.; Lemaire, M.T.; Thompson, L. K. Inorg. Chem. 2001, 40,6521-6524

42. Brook, D.J.R.; Richardson, C.J.; Haller, B.C.; Hundley, M.; Yee, G.T. Chem. Commun. 2010, 46, 6590-6592.

43. Brook, D.J.R.; Fornell, S.; Stevens, J.E.; Noll, B.: Koch, T.H.; Eisfeld, W. Inorg. Chem. 2000, 39, 562-567.

44. Brook, D.J.R.; Yee, G.T.; Hundley, M.; Rogow, D.; Wong, J.; Van-Tu, K. Inorg. Chem. 2010, 49, 8573-8577.

45. Haley, C.A.C.; Maitland, P. Journal of the Chemical Society (Resumed), 1951, 3155-3174.

46. Dutta, M.; Movassat, M.; Brook, D.J.R.; Oliver, A.; Ward, D. Supramolecular Chemistry 2011, 23, 632-643.

47. Barbiou, M.; Ruben, M.; Blasen, G.; Kyritsakas, N.; Chacko, E.; Dutta, M.; Radekovich, O.; Lenton, K.; Brook, D.J.R.; Lehn, J. Eur. J. Inorg. Chem. 2006, 4, 784-792

48. Callabretta, R.; Gallina, C.; Giordano, C. Synthesis 1991, 536-539.

49. Bleany, B.; Bowers, K.D. Proc. Roy. Soc. London 1952, 451-465.

50. Brook, D.J.R.; Yee, G.T. J. Org. Chem. 2006, 71, 4489-4895. 
51. Brustolon, M.; Giamello, E. Electron Paramagnetic Resonance: A Practitioner's Toolkit. Hoboken, New Jersey: John Wiley \& Sons, Inc., 2009, $28-31$ 